\title{
Working
}

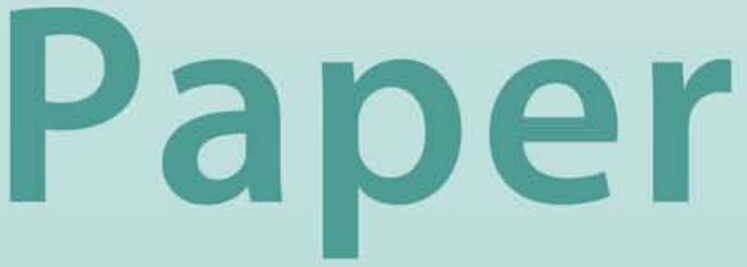




\section{The Impact of Introducing a Minimum Wage on Business Cycle Volatility: A Structural Analysis for Hong Kong SAR}

Nathan Porter and Francis Vitek 


\title{
IMF Working Paper
}

Asia and Pacific Department

\section{The Impact of Introducing a Minimum Wage on Business Cycle Volatility: A Structural Analysis for Hong Kong SAR}

\section{Prepared by Nathan Porter and Francis Vitek ${ }^{1}$}

Authorized for distribution by Nigel Chalk

December 2008

\begin{abstract}

\section{This Working Paper should not be reported as representing the views of the IMF.} The views expressed in this Working Paper are those of the author(s) and do not necessarily represent those of the IMF or IMF policy. Working Papers describe research in progress by the author(s) and are published to elicit comments and to further debate.
\end{abstract}

We study the impact of a minimum wage on business cycle volatility, depending upon its coverage and adjustment mechanism. As with other small open economies, Hong Kong SAR is vulnerable to external shocks, with its exchange rate regime precluding active monetary policy. Adjustment to past shocks has relied on flexible domestic prices. We find that a minimum wage affecting 20 percent of employees would amplify output volatility by 0.2 percent to 9.2 percent, and employment volatility by -1.2 percent to 7.8 percent. A fixed wage or indexation to consumption price inflation increases volatility most. Indexation to wage inflation or unit labor cost growth is preferable, largely preserving labor market flexibility.

JEL Classification Numbers:C11, C13, C32, E24, E27, F41

Keywords: Minimum wage, indexation mechanism, business cycle volatility, dynamic stochastic general equilibrium model, unobserved components model, market flexibility, small open economy

Author’s E-Mail Address:nporter@imf.org; fvitek@imf.org

\footnotetext{
${ }^{1}$ The authors gratefully acknowledge comments and suggestions received from Nigel Chalk, Hong Kong SAR's Labor Department, and seminar participants at the Hong Kong Monetary Authority.
} 


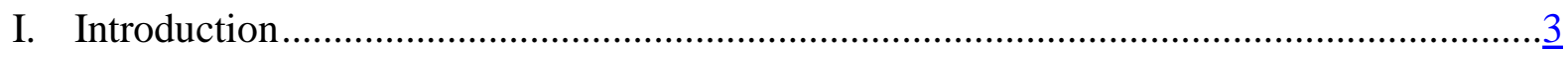

II. Changing Inequality and the Wage Protection Movement ...........................................

III. The Theoretical and Empirical Frameworks........................................................... $\underline{5}$

IV. What Impact Will a Minimum Wage Have on Macroeconomic Adjustment?...................

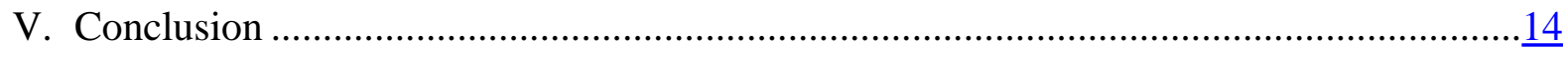

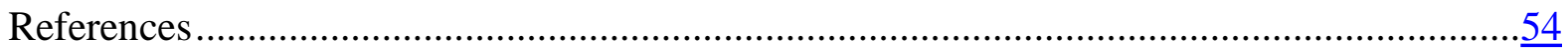

Figures

1. Nonparametric Estimates of the Labor Income Distribution ........................................... $\underline{5}$

2. Increase in Business Cycle Volatility Caused by Introducing a Minimum Wage............... $\underline{9}$

3. Impulse Responses to a Domestic Supply Shock ....................................................10

4. Impulse Responses to a Foreign Supply Shock ......................................................11

5. Impulse Responses to a Domestic Demand Shock ....................................................11

6. Impulse Responses to a Foreign Demand Shock .....................................................12

7. Impulse Responses to a Domestic Monetary Conditions Shock ....................................13

8. Impulse Responses to a Foreign Monetary Conditions Shock .......................................14

Tables

1. Hong Kong SAR: Gini Coefficients for Income Inequality, 1996-2006 .........................

2. Increase in Business Cycle Volatility Caused by Introducing a Minimum Wage................ $\underline{8}$

\section{Appendices}

1. Model Development, Estimation Procedure, and Estimation Results ............................16

2. Description of the Data Set ................................................................................

Appendix Tables

I.1 Deterministic Steady State Equilibrium Values of Great Ratios …...............................48

I.2 Parameter Estimation Results ...................................................................... 51 


\section{INTRODUCTION}

Two years ago, amid concerns over growing income inequality in Hong Kong SAR, the government introduced a voluntary minimum wage for selected low wage occupations. A review of this voluntary scheme recently concluded that it had been rather ineffective in providing income support to the working poor. Given the ineffectiveness of the voluntary scheme, the government of Hong Kong now plans to introduce a universal statutory minimum wage. While this will provide wage protection, the government realizes the need to balance several factors-including the impact of the minimum wage on inequality, employment, business operations, inflation, and overall competitiveness—when designing the minimum wage.

As a relatively small and open economy, serving as an intermediating hub for international trade and investment flows, Hong Kong SAR is considerably exposed to shocks transmitted via trade and financial channels. Adjustment to these shocks has historically relied heavily on the flexibility of domestic goods, labor, and asset prices, given that its rigid exchange rate arrangement (the Linked Exchange Rate System) precludes a stabilization role for monetary policy, and with fiscal policy constrained by lags and constitutional limits. In other words, the monetary and fiscal arrangements in Hong Kong place a premium on this market flexibility. Consequently, the introduction of the minimum wage should be done in a way which preserves Hong Kong’s domestic price flexibility.

This paper analyzes the impact of introducing a statutory minimum wage on business cycle volatility and adjustment to shocks for different levels of coverage, and various types of adjustment mechanism. This analysis is conducted within the framework of a dynamic stochastic general equilibrium (DSGE) model of a small open economy, estimated to fit data for Hong Kong SAR and its most influential trading partner, the United States. This model is similar to that used by Porter and Vitek (2008) to understand the drivers of Hong Kong's saving and investment flows. However, reflecting the challenge of understanding the impact of a minimum wage, we have augmented the labor market of that model. In particular, households differ with a fixed measure supplying unskilled labor and paid the binding legislated minimum wage, with the remaining households supplying skilled labor and permitted to optimally reset their wage when (randomly) able to do so. Consequently, skilled individuals participate in the (relatively more) flexible labor market, while unskilled individuals participate in a separate and highly regulated labor market, where wages are set according to the rules governing the minimum wage. Conditional on a current minimum wage, the wage is assumed to adjust following some set indexation rule. In particular, we compare five alternative mechanisms for adjusting the minimum wage: no indexation (fixed minimum wage), indexation to aggregate wage inflation, indexation to unit labor cost growth, indexation to consumption price inflation, and indexation to the sum of consumption price inflation and average labor productivity growth. 
We find that introducing a minimum wage in Hong Kong SAR has the potential to elevate macroeconomic volatility and distort the dynamic response of the economy to shocks. Indeed, introducing a minimum wage which binds for 20 percent of households is estimated to amplify the volatility of output over the business cycle by 0.2 percent to 9.2 percent, and of employment by -1.2 percent to 7.8 percent. These wide ranges reveal the sensitivity of the effects of introducing a minimum wage to the mechanism for adjusting it over time. We also find that the resilience of the economy of Hong Kong to shocks affecting its external price competitiveness can be largely preserved through judicious choice of the mechanism for adjusting the minimum wage over time. In particular, indexation of the minimum wage to aggregate wage inflation is found to dominate alternative adjustment mechanisms, with no indexation or indexation to consumption price inflation particularly boosting volatility. This result is robust to variation in the coverage of the minimum wage and the source of business cycle fluctuations.

The organization of this paper is as follows. The next section describes the changing pattern of income inequality over time, as well as the broad parameters of the voluntary minimum wage scheme trialed by the government between 2006 and 2008. The DSGE model of Hong Kong SAR, the estimation technique, and the estimation results are outlined in section three. Inference on the effects of introducing a minimum wage in Hong Kong on the basis of unconditional standard deviations and impulse response functions is conducted in section four. Finally, section five offers conclusions and recommendations for further research.

\section{Changing Inequality and the Wage Protection Movement}

Rising inequality has become a significant policy issue in Hong Kong SAR in recent years. Although the extent of inequality is hard to measure, there are clear signs that inequality has increased over the past decade. Using data from successive population censuses, the government has estimated gini coefficients, which show that inequality based on household (rather than individual) income increased between 1996 and 2006. Tax and transfer payments have tended to mitigate the increase in income inequality, but inequality remains high.

A similar pattern of rising inequality is

\begin{tabular}{|lccc|}
\hline \multicolumn{5}{|c|}{ Table 1. Hong Kong SAR: Gini Coefficients for Income } \\
Inequality, 1996-2006 & & \\
\hline & 1996 & 2001 & 2006 \\
\hline Original hous ehold monthly income & 0.518 & 0.525 & 0.533 \\
Post tax & 0.508 & 0.515 & 0.521 \\
Post tax and transfer & 0.466 & 0.470 & 0.475 \\
Per capita and post tax and transfer & 0.427 & 0.421 & 0.427 \\
\hline Source: 2006 Population By-Census Thematic Report: Household \\
Income Distribution in Hong Kong. \\
\hline
\end{tabular}
indicated by looking at average monthly income data. Using data on employment and average wages by occupation (and kernel density estimation), Figure 1 shows that not only has there been substantial cross-sectoral inequality for some time, but that it has increased over the past decade. In particular, reflecting apparent segmentation of Hong Kong SAR's labor market between skilled and unskilled workers, the income distribution is bimodal. The distance between these modes is large relative to the support of the labor income distribution 
(around half of the support), and most of its mass is concentrated under the lower mode. As measured by the standard deviation of labor income, inequality increased by 22.6 percent from 1997 to 2007. To provide further information on the extent of inequality and inform the setting of the minimum wage, the government is planning to enhance the extent of available labor market and income data.

Figure 1. Nonparametric Estimates of the Labor Income Distribution 1/
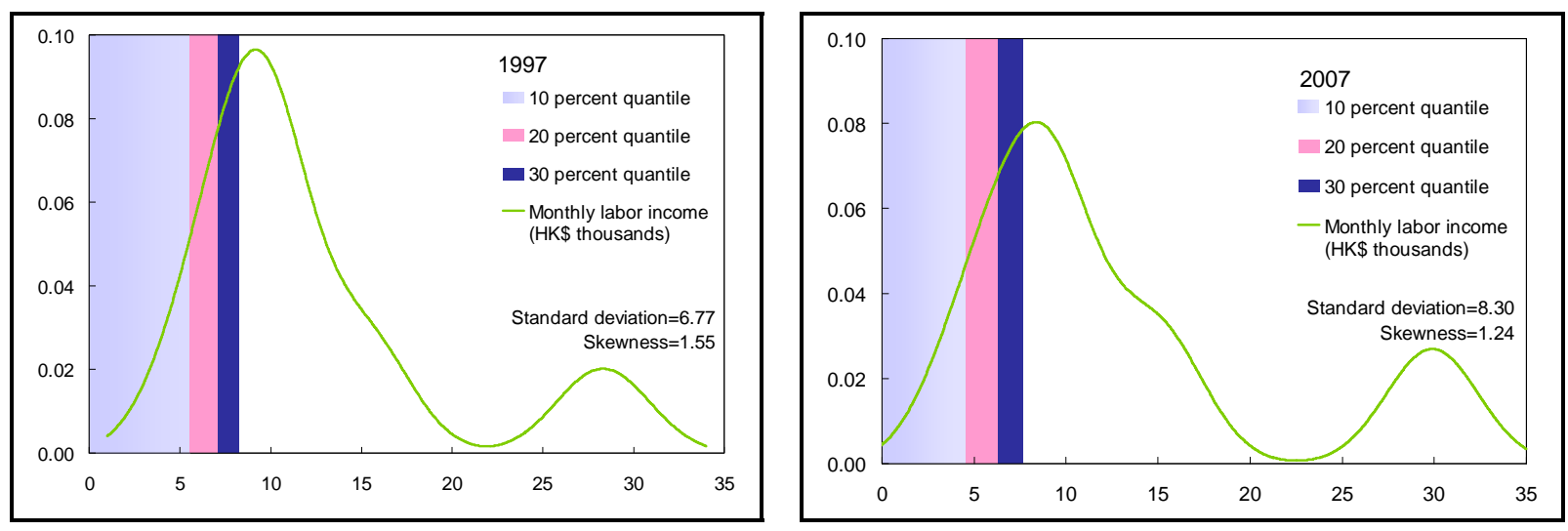

1/ Probability density functions are estimated with a normal kernel employing a bandwidth of 2.5 .

Reflecting concerns over the apparent rise in inequality, the government launched a voluntary minimum wage - the Wage Protection Movement-in October 2006. Its main aim was to provide a living income to workers in two low wage occupations: cleaners and security guards. Companies that participated in the scheme agreed to offer their cleaning workers and security guards wages at least equal to the relevant average market wage prevailing at the time (as measured by the Census and Statistics Department). They were also to enter into a written contract with those workers they directly employed, as well as their contractors and subcontractors providing cleaning and security services. A review of the scheme, completed in October 2008, found that although there had been an increase in the number of workers benefiting from the scheme over the two years, the performance of the scheme had been unsatisfactory. As a result, the government is now committed to moving forward with the legislative work for a statutory minimum wage.

\section{THE THEORETICAL AND EMPIRICAL FRAMEWORKS}

\section{The Theoretical Framework}

This paper analyzes the impact of introducing a statutory minimum wage on business cycle volatility and adjustment to shocks as its coverage and adjustment mechanism varies. This analysis is conducted within the framework of a DSGE model of a small open economy, estimated to fit data for Hong Kong SAR and its most influential trading partner, the United States. With the model much the same as that in Porter and Vitek (2008), in this section we only provide a brief summary of it, focusing on its novel features. Complete descriptions of the model, estimation procedure, and estimation results are laid out in Appendix I. 
The structure of the DSGE model is fairly standard, although the labor market has been enhanced to differentiate types of labor (those with low skills who are subject to the minimum wage and those with high skills who are not) and, given Hong Kong SAR's nature as a trading hub, there is a detailed entrepôt trade sector. Following Smets and Wouters (2003), this DSGE model features short run nominal price and wage rigidities generated by monopolistic competition, staggered reoptimization, and partial indexation in output and labor markets. This staggered wage setting is applicable to high skilled individuals who have monopoly power in the labor market, while those with low skills are subject to the minimum wage. Following Christiano, Eichenbaum and Evans (2005), inflation inertia and output persistence are enhanced with habit persistence in consumption and employment, adjustment costs in investment, and variable capital utilization. Following Monacelli (2005), incomplete exchange rate pass through is generated by short run nominal price rigidities in the import and export markets. This theoretical framework is extended to allow for entrepôt trade.

The principal novelty of the model developed here is segmentation of the labor market between those with low incomes that are protected by the minimum wage, and those with higher incomes subject to typical wage rigidities. For tractability, we assume that a there are a fixed proportion of households $\varphi^{L}$ that are subject to minimum wage $W_{t}^{u}$, and that this wage binds in all states of the economy for these individuals. The remaining skilled individuals set their wages $W_{t}^{s}$ subject to randomly arriving reoptimization opportunities. Given this structure, the aggregate wage (in deviations from steady state and relative to their productivity $A_{t}$ ) is given by:

$$
\ln \frac{\hat{W}_{t}}{\hat{A}_{t}}=\varphi^{L} \ln \frac{\hat{W}_{t}^{u}}{\hat{A}_{t}^{u}}+\left(1-\varphi^{L}\right) \ln \frac{\hat{W}_{t}^{s}}{\hat{A}_{t}^{s}} .
$$

The minimum wage is assumed to adjust over the business cycle in a simple, transparent and automatic way. Specifically, it is assumed to be potentially indexed to up to three variables: aggregate wage $W_{t}$ inflation, average labor productivity $y_{t}$ growth, and consumption price $P_{t}^{C}$ inflation. The indexed minimum wage therefore satisfies

$$
\ln W_{t}^{u}=\gamma^{L_{u}, W} \ln \left(\frac{W_{t-1}}{W_{t-2}}\right)+\gamma^{L_{l}, P} \ln \left(\frac{P_{t-1}^{C}}{P_{t-2}^{C}}\right)+\gamma^{L_{l}, y} \ln \left(\frac{y_{t-1}}{y_{t-2}}\right)+\ln W_{t-1}^{u},
$$

where $0 \leq \gamma^{L_{l}, W} \leq 1,0 \leq \gamma^{L_{l}, P} \leq 1$ and $0 \leq \gamma^{L_{l}, Y / L} \leq 1$ are the weights attached to the various indexation variables. We denote our five experiments by $\left\{\mathcal{M}_{m}\left(\varphi^{L}\right)\right\}_{m=0}^{5}$, where $\varphi^{L}$ measures the proportion of households subject to a binding minimum wage, and $m$ is the type of indexation. Under $\mathcal{M}_{0}$ there does not exist a minimum wage, represented by $\varphi^{L}=0$. Under $\mathcal{M}_{1}(\cdot)$ the minimum wage is not indexed, represented by $\gamma^{L_{u}, W}=0, \gamma^{L_{u}, P}=0$ and $\gamma^{L_{u}, y}=0$. 
In contrast, under $\mathcal{M}_{2}(\cdot)$ the minimum wage is fully indexed to past aggregate wage inflation, represented by $\gamma^{L_{u}, W}=1, \gamma^{L_{u}, P}=0$ and $\gamma^{L_{u}, y}=0$. Under $\mathcal{M}_{3}(\cdot)$ the minimum wage is fully indexed to past aggregate wage inflation less average labor productivity growth, represented by $\gamma^{L_{u}, W}=1, \gamma^{L_{u}, P}=0$ and $\gamma^{L_{u}, y}=-1$. Under $\mathcal{M}_{4}(\cdot)$ the minimum wage is fully indexed to past consumption price inflation, represented by $\gamma^{L_{u}, W}=0, \gamma^{L_{u}, P}=1$ and $\gamma^{L_{u}, y}=0$. Finally, under $\mathcal{M}_{5}(\cdot)$ the minimum wage is fully indexed to the sum of past consumption price inflation and average labor productivity growth, represented by $\gamma^{L_{u}, W}=0, \gamma^{L_{u}, P}=1$ and $\gamma^{L_{u}, y}=1$.

\section{The Empirical Framework}

Following Vitek (2008a, 2008b), estimation and inference is based on an approximate linear unobserved components representation of this DSGE model of a small open economy. Parameters and unobserved components are jointly estimated over the recent Linked Exchange Rate System period with a Bayesian procedure, conditional on prior information concerning the values of parameters, and judgment concerning the paths of trend components. For a detailed description of this empirical framework, please refer to Appendix I.

\section{What Impact Will a Minimum Wage HaVe on Macroeconomic AdJustment?}

We analyze the effects of introducing a statutory minimum wage on business cycle volatility in Hong Kong SAR as its coverage and adjustment process varies using unconditional standard deviations and impulse response functions. In an open economy, business cycles are manifestations of the cumulative effects of a variety of nominal and real shocks originating domestically and abroad, and unconditional standard deviations summarize their average volatility. In contrast, impulse response functions reveal the dynamic response of the economy to isolated shocks. In our experiment we assume for illustrative purposes that the proportion of households subject to the minimum wage is an increasing function of the level of the minimum wage, but is centered around 20 percent.

\section{Unconditional Standard Deviations}

Constraints on the conduct of monetary and fiscal policy in Hong Kong SAR have historically been counterbalanced by relatively flexible output and labor markets, which underpin the resilience of the economy to shocks impinging on its external price competitiveness. Given its strong trade and financial linkages with the rest of the world, the exposure of the economy of Hong Kong to such shocks is profound. The estimated effects of introducing a minimum wage on the business cycle volatility of key output and labor market variables in Hong Kong are depicted in Figure 2. We compare the increase in the unconditional standard deviations of output price inflation, output, wage inflation and employment across two dimensions of the minimum wage: its coverage, and the process by which it is adjusted over time. 
Estimated unconditional standard deviations indicate that introducing a minimum wage in Hong Kong SAR which binds for 20 percent of households will amplify the volatility of output over the business cycle by 0.2 percent to 9.2 percent, and of employment by -1.2 percent to 7.8 percent. These wide ranges reveal the sensitivity of the effects of introducing a minimum wage to the mechanism for adjusting it over time. Introducing a minimum wage without indexing it is estimated to inflate the business cycle volatility of output by 9.2 percent at the 20 percent coverage level, and of employment by 6.6 percent. Nevertheless, introducing a minimum wage indexed to aggregate wage inflation is estimated to amplify the volatility of output over the business cycle by only 0.2 percent at this coverage level, and of employment by only 0.2 percent. Introducing a minimum wage indexed to other variables is estimated to inflate business cycle volatility to intermediate degrees.

Table 2. Increase in Business Cycle Volatility Caused by Introducing a Minimum Wage 1/

\begin{tabular}{lrrrrr}
\hline & \multicolumn{5}{c}{ Mechanism } \\
\cline { 2 - 6 } & $\mathcal{M}_{1}(0.2)$ & $\mathcal{M}_{2}(0.2)$ & $\mathcal{M}_{3}(0.2)$ & $\mathcal{M}_{4}(0.2)$ & $\mathcal{M}_{5}(0.2)$ \\
\hline Output price inflation & -7.3 & 0.4 & 7.2 & -4.8 & -10.3 \\
Output & 9.2 & 0.2 & 3.8 & 8.5 & 6.2 \\
Wage inflation & -17.9 & -10.5 & -3.5 & -7.3 & 6.3 \\
Employment & 6.6 & 0.2 & -1.2 & 5.6 & 7.8 \\
\hline
\end{tabular}

1/ Reports the increase in the unconditional standard deviations of cyclical components caused by introducing minimum wage mechanism $\mathcal{M}_{m}(0.2)$. Unconditional standard deviations are calculated with a Monte Carlo simulation with 999 replications for $2 T$ periods, discarding the first $T$ simulated observations to eliminate dependence on initial conditions, where $T$ denotes the observed sample size.

Indexation of the minimum wage to aggregate wage inflation restores output and labor market efficiency more rapidly in response to shocks than alternative adjustment mechanisms. In response to a shock which affects external price competitiveness, restoring labor market efficiency requires realigning the marginal rates of substitution of households between leisure and consumption with their after tax real wages. A subset of the skilled households are able to adjust their wages optimally in a given period (doing so to equate the expected present value of their marginal rates of substitution between leisure and consumption with the expected present value of their after tax real wages). This implies that the wages received by skilled households adjust relatively quickly to restore their labor market efficiency conditions. Since, in this one sector model, the marginal rates of substitution between leisure and consumption are highly positively correlated across skilled and unskilled households, if the minimum wage received by unskilled households is fully indexed to past aggregate wage inflation, then it also adjusts relatively quickly to restore their labor market efficiency conditions.

For a small open economy with a fixed exchange rate regime, no indexation or indexation of the minimum wage to consumption price inflation amplifies distortions in the output and labor markets. Without indexation (or some other adjustment) there is no way for real wages to adjust after a shock. Depending on the shock, indexation to consumption price inflation 
can lead real wages to adjust in the wrong direction-in response to a terms of trade shock which affects the price of imports, real wages must adjust in the opposite direction to maintain the external price competitiveness of the labor market. Indexation of the minimum wage to consumption price inflation impedes this adjustment, as the price of consumption moves in tandem with the price of imports.

Figure 2. Increase in Business Cycle Volatility Caused by Introducing a Minimum Wage 1/
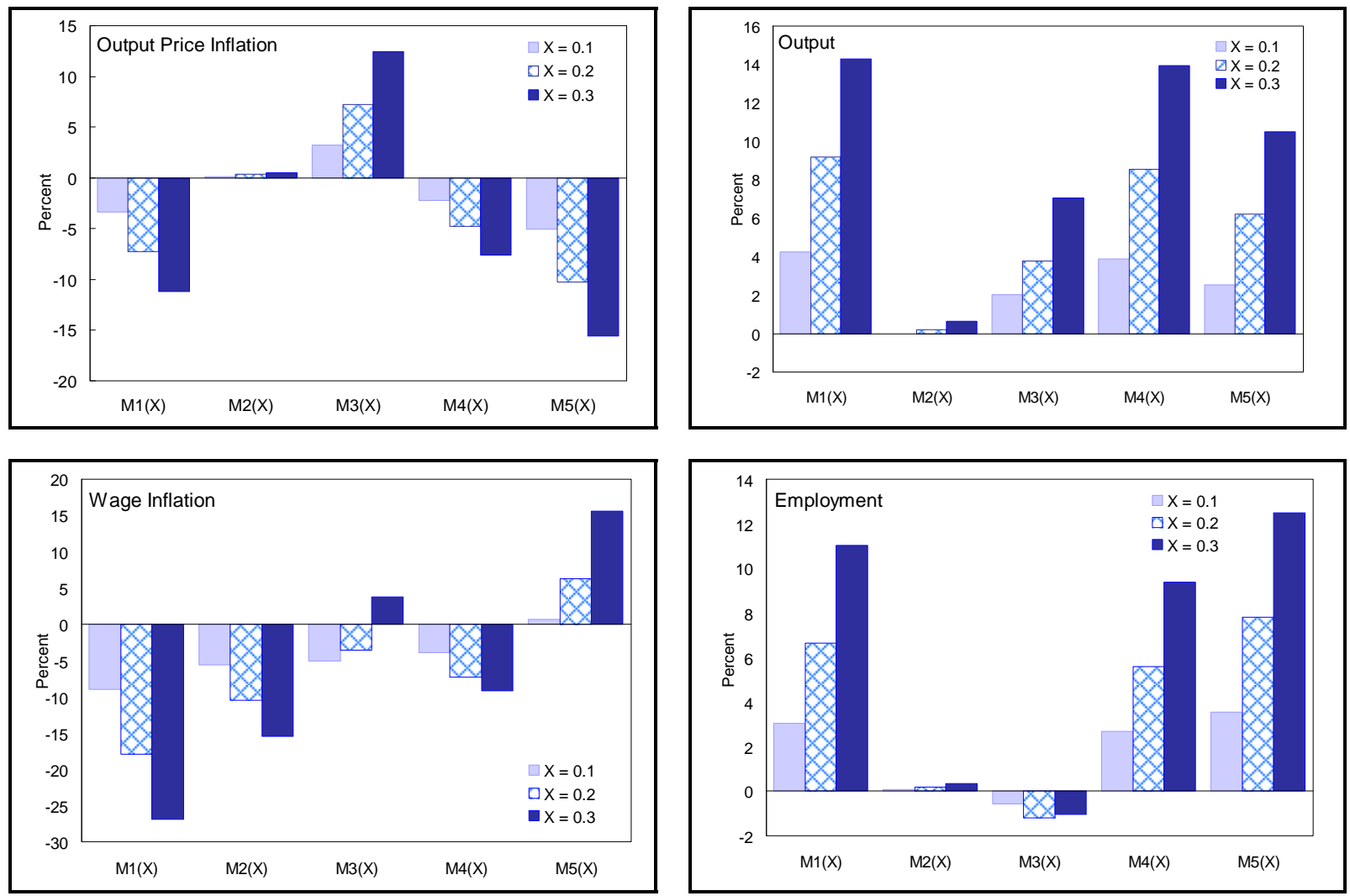

$1 /$ Depicts the increase in the unconditional standard deviations of cyclical components caused by introducing minimum wage mechanism $\mathcal{M}_{m}(\cdot)$. Unconditional standard deviations are calculated with a Monte Carlo simulation with 999 replications for $2 T$ periods, discarding the first $T$ simulated observations to eliminate dependence on initial conditions, where $T$ denotes the observed sample size.

\section{Impulse Response Functions}

By reducing labor market flexibility, introducing a minimum wage impedes the restoration of external price competitiveness following shocks. However, the size of these impediments may be expected to vary depending on the source of business cycle fluctuations. Estimated impulse responses of key output and labor market variables in Hong Kong SAR to a variety of nominal and real shocks originating domestically and abroad are compared in Figures 3-8, across alternative mechanisms for adjusting the minimum wage over time. In particular, we consider the impulse responses of output price inflation, output, wage inflation and employment to the following shocks: domestic and foreign supply shocks, domestic and foreign demand shocks, and domestic and foreign monetary conditions shocks. 
Estimated impulse responses indicate that introducing a minimum wage has the potential to distort the dynamic responses of the output and labor markets to shocks. Relative to alternative adjustment mechanisms, indexation of the minimum wage to aggregate wage inflation least distorts the impulse responses of output and employment, irrespective of the source of business cycle fluctuations, for similar reasons to those given above. Under alternative adjustment mechanisms, the peak responses of output and employment to domestic and foreign supply and monetary conditions shocks are generally amplified. Nevertheless, the peak responses of output and employment to domestic and foreign demand shocks are essentially invariant to the introduction of a minimum wage.

Figure 3. Impulse Responses to a Domestic Supply Shock 1/
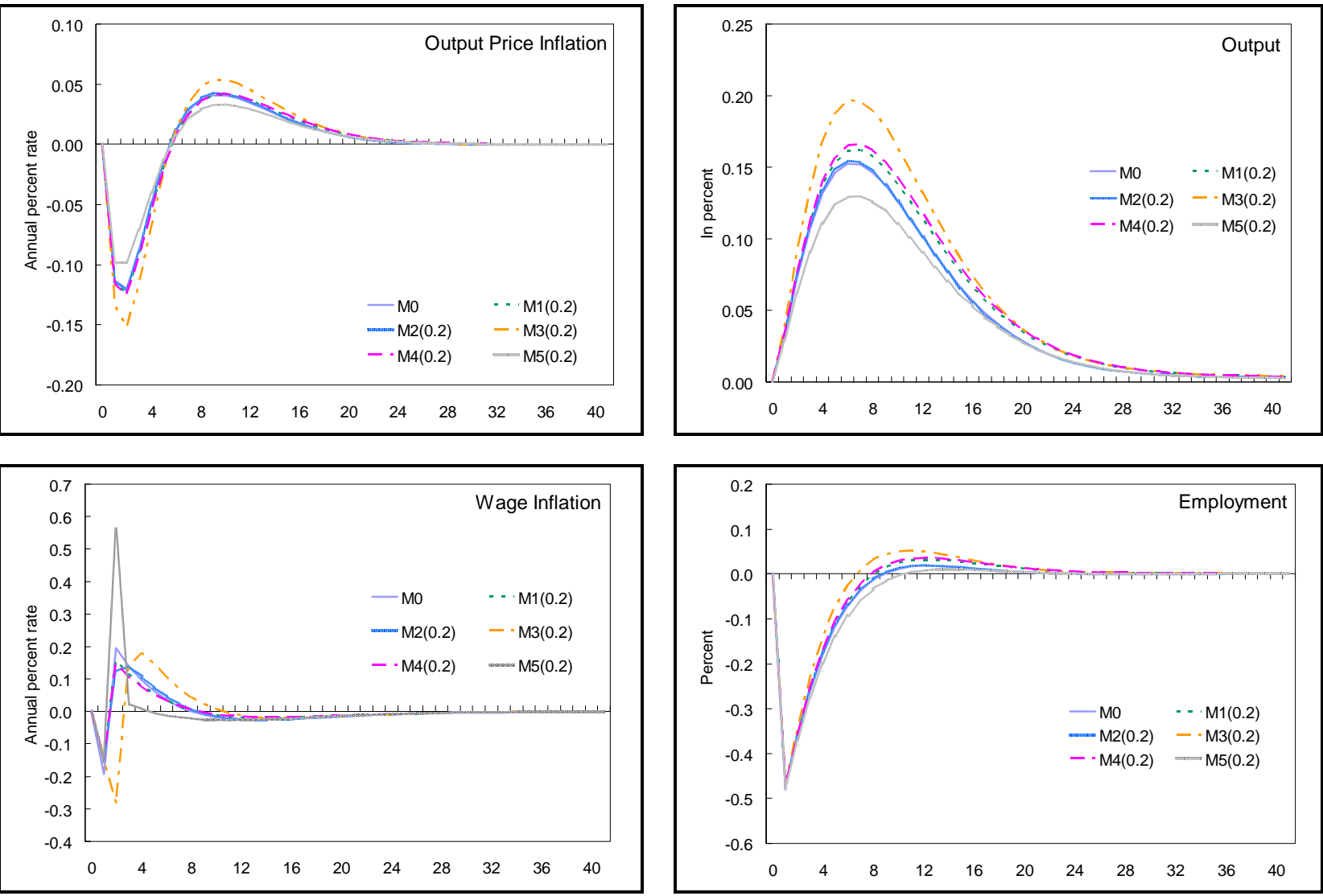

$1 /$ Impulse responses to a unit standard deviation domestic labor productivity shock under minimum wage mechanism $\mathcal{M}_{m}(0.2)$

In response to a domestic supply shock, in the form of an increase in labor productivity in Hong Kong SAR, output rises and employment falls. Unless indexed to aggregate wage inflation, a minimum wage distorts the responses of the output and labor markets. 
Figure 4. Impulse Responses to a Foreign Supply Shock 1/
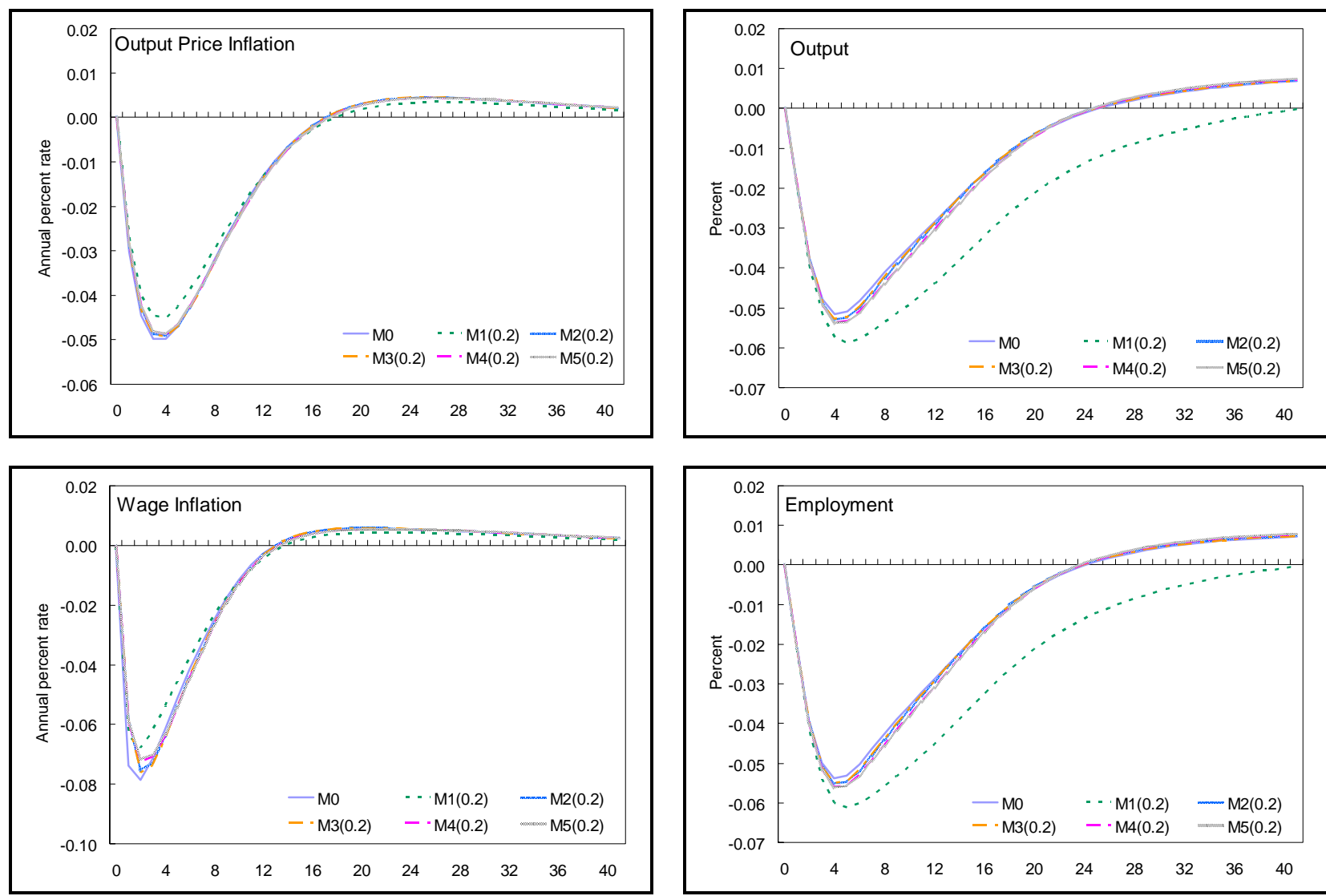

$1 /$ Impulse responses to a unit standard deviation foreign labor productivity shock under minimum wage mechanism $\mathcal{M}_{m}(0.2)$.

In response to a foreign supply shock, in the form of an increase in labor productivity in the United States, prices and wages both decline to restore the external price competitiveness of the output and labor markets. During this period of adjustment, excess capacity in the output and labor markets arises. In this case, the type of indexation does not matter, but a minimum wage which is not indexed significantly amplifies this underutilization of resources.

Figure 5. Impulse Responses to a Domestic Demand Shock 1/
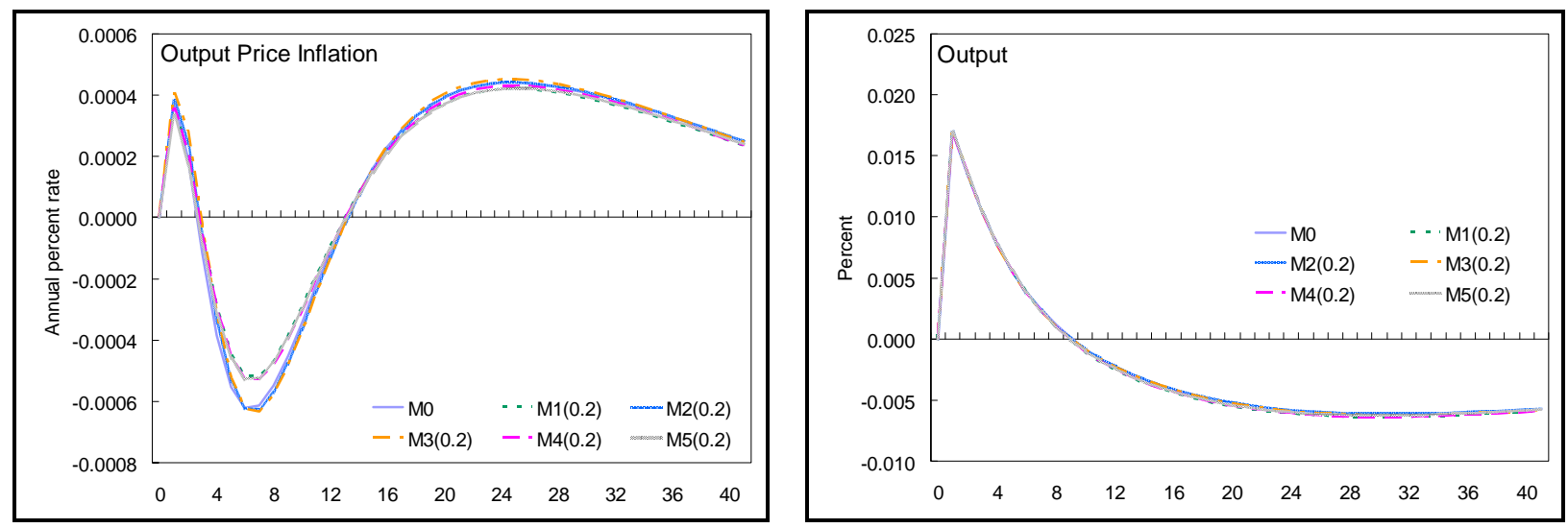

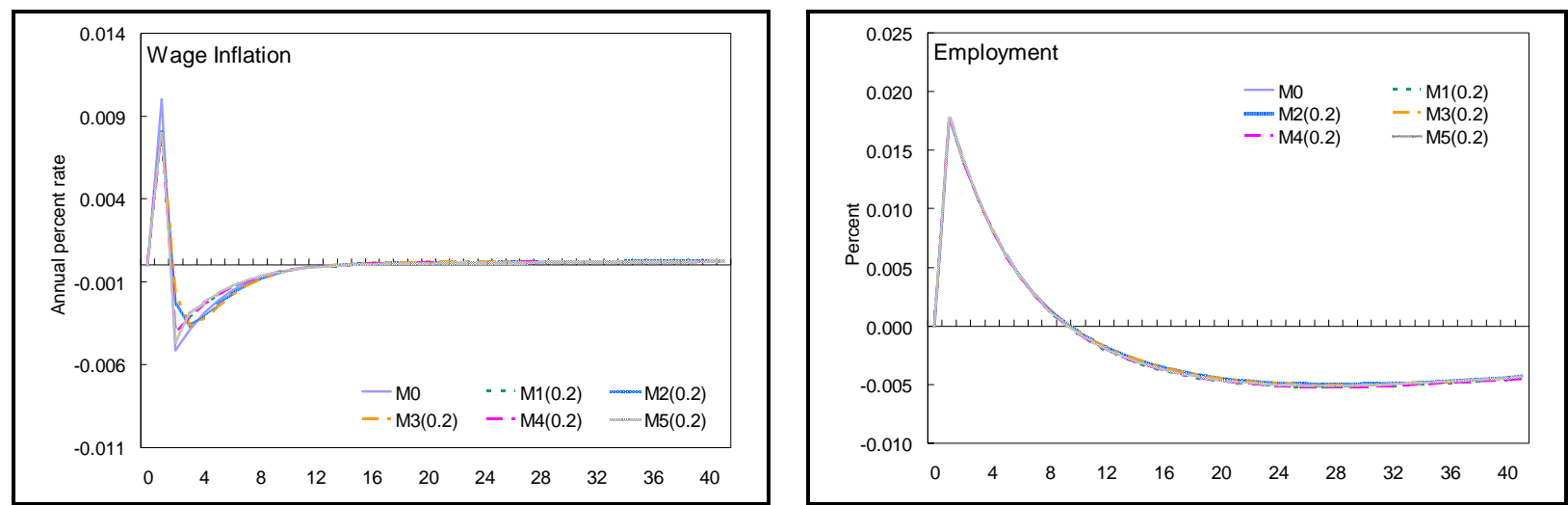

$1 /$ Impulse responses to a unit standard deviation domestic fiscal expenditure shock under minimum wage mechanism $\mathcal{M}_{m}(0.2)$.

A domestic demand shock, in the form of an increase in government expenditures in Hong Kong SAR, generates capacity pressures in the output and labor markets. A minimum wage does not exacerbate these capacity pressures, but does distort the subsequent adjustments of the output and labor markets.

Figure 6. Impulse Responses to a Foreign Demand Shock 1/
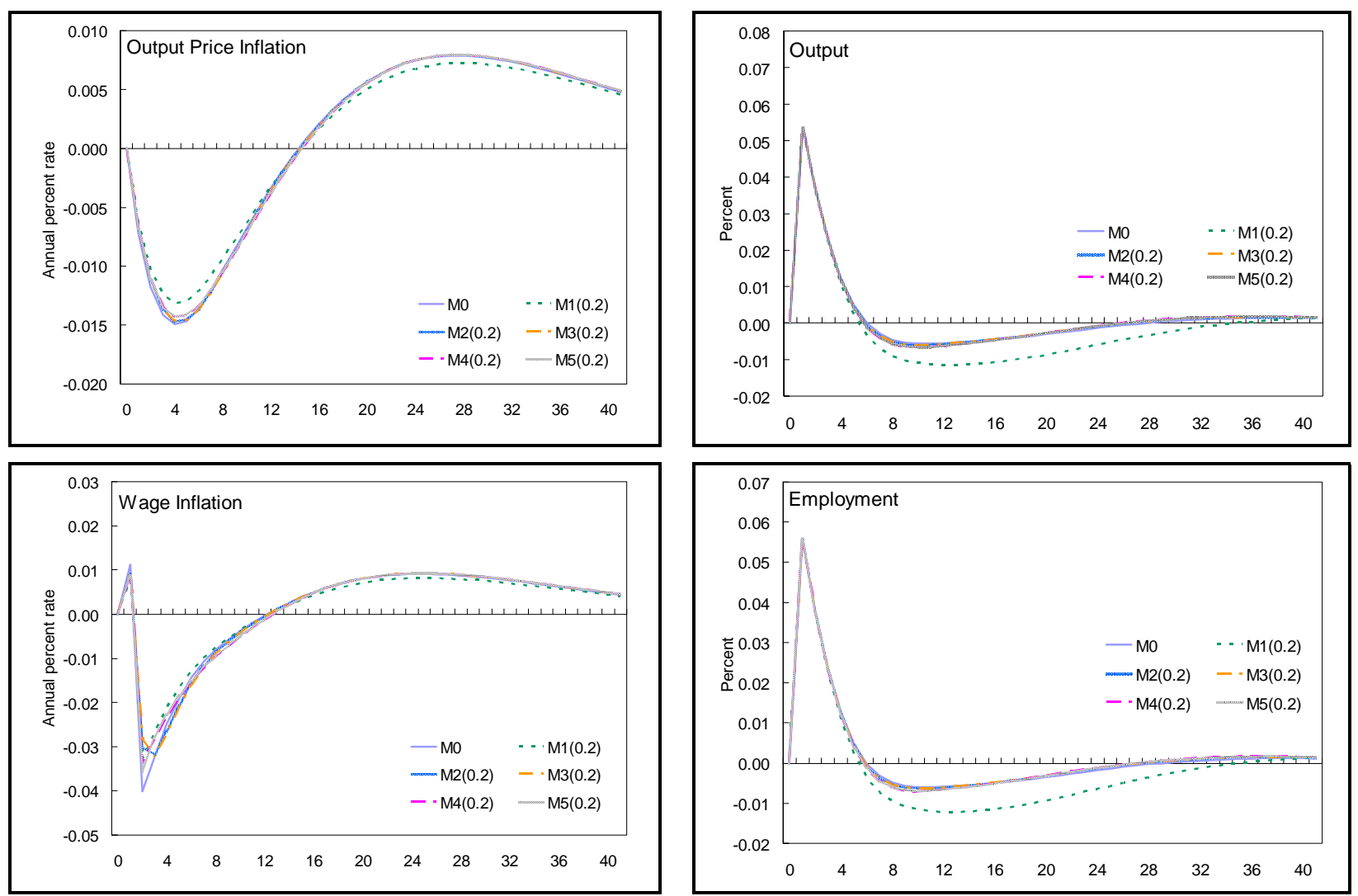

1/ Impulse responses to a unit standard deviation foreign fiscal expenditure shock under minimum wage mechanism $\mathcal{M}_{m}(0.2)$. 
A foreign demand shock, in the form of an increase in government expenditures in the United States, generates capacity pressures in the output and labor markets. A minimum wage does not exacerbate these capacity pressures, but does cause excessive subsequent downwards adjustments of output and employment unless indexed, although the form of indexation does not matter.

Figure 7. Impulse Responses to a Domestic Monetary Conditions Shock 1/
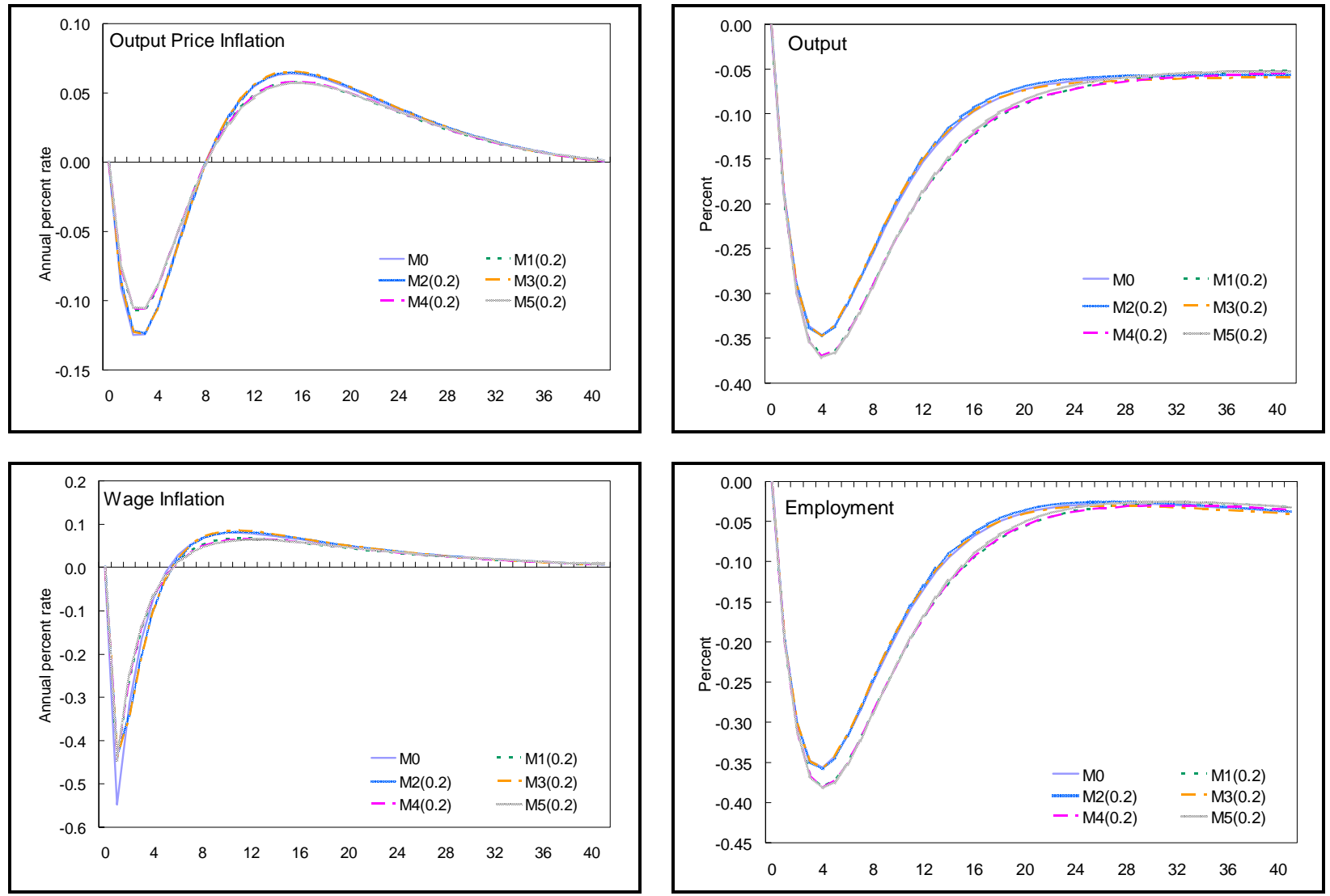

$1 /$ Impulse responses to a unit standard deviation foreign exchange transaction cost shock under minimum wage mechanism $\mathcal{M}_{m}(0.2)$.

Under its Linked Exchange Rate System, deviations from uncovered interest parity which exert nominal depreciation pressure in Hong Kong SAR necessitate offsetting monetary tightening to stabilize the nominal exchange rate. In response to this tightening of monetary conditions, prices and wages both decline, while excess capacity in the output and labor markets arises. Unless indexed to aggregate wage inflation or unit labor cost growth, a minimum wage amplifies this underutilization of resources. 
Figure 8. Impulse Responses to a Foreign Monetary Conditions Shock 1/
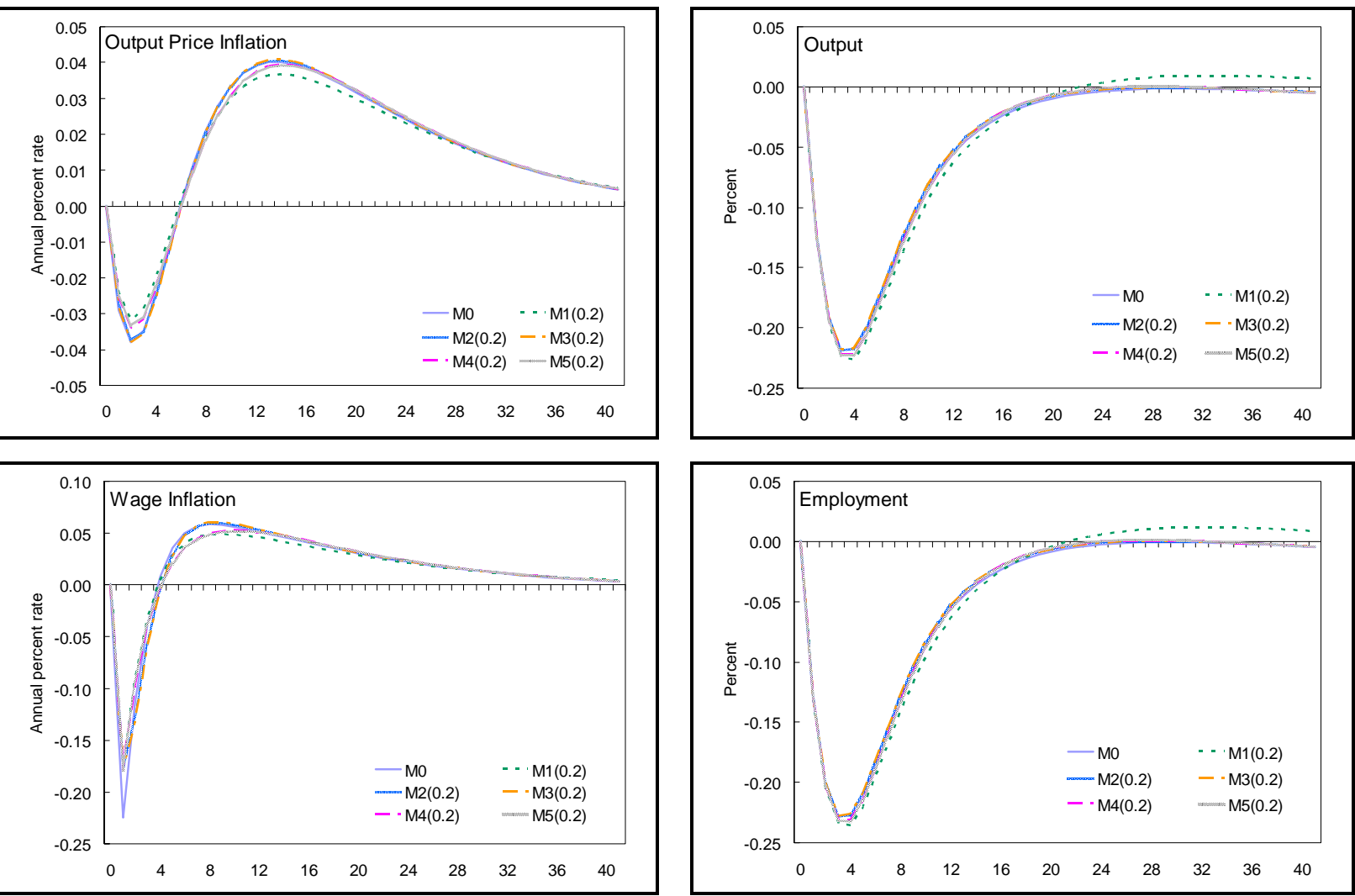

1/ Impulse responses to a unit standard deviation foreign monetary policy shock under minimum wage mechanism $\mathcal{M}_{m}(0.2)$.

In response to a tightening of monetary conditions in the United States, prices and wages both decline, while excess capacity in the output and labor markets arises. These responses reflect the corresponding tightening of monetary conditions in Hong Kong SAR under its Linked Exchange Rate System. Unless indexed to aggregate wage inflation, a minimum wage amplifies this underutilization of resources, although differences in the adjustment under the various indexation schemes are small.

\section{Conclusion}

By lessening income inequality, introducing a minimum wage may be expected to promote social stability. However, by reducing labor market flexibility, it also has the potential to elevate macroeconomic volatility and distort the dynamic response of the economy to shocks. This paper estimates that introducing a minimum wage in Hong Kong SAR which binds for 20 percent of households will amplify the volatility of output over the business cycle by 0.2 percent to 9.2 percent, and of employment by -1.2 percent to 7.8 percent, depending on the process by which it is adjusted over time. The choice of 20 percent coverage of the minimum wage is purely for illustrative purposes, with the ultimate coverage a social choice yet to be made by the government of Hong Kong. Indexation of the minimum wage to aggregate wage inflation is found to dominate alternative adjustment mechanisms, although 
indexation to unit labor cost growth also performs well. In contrast, a fixed minimum wage or indexation to consumption price inflation tends to boost output and employment volatility by wide margins, irrespective of the coverage of the minimum wage and the source of business cycle fluctuations. The dominance of indexation to aggregate wage indexation reflects that, in our model economy, wages for skilled workers are relatively flexible, respond to the same shocks as those impinging on the low skilled labor market, and are relatively unaffected by distortions, thereby allowing skilled wages to move in a way that allows the economy to quickly adjust to shocks. If skilled wages were further distorted in some way, or if the low skilled labor market was sufficiently segmented (i.e., driven by different factors), then low skilled unit labor cost growth may be preferable for indexation. Nonetheless, indexation to some measure of labor cost increases (aggregate wage inflation or unit labor cost growth) will always dominate a fixed minimum wage or indexation to consumption price inflation.

While this paper provides a number of broad lessons for choosing the parameters that govern a minimum wage, given its model based nature, it necessarily glosses over some important practical implementation issues. These include the setting of the initial minimum wage (and therefore its coverage), the measurement of labor market indicators, as well as specific sectoral effects. The level of the minimum wage is a social choice, with various tradeoffs having to be made. Although we do not have conclusions on this, choosing a conservative level initially, assessing the resulting social and economic consequences and, if necessary, then adjusting its level would seem a sensible approach. The minimum wage could also be supplemented with social welfare payments to provide poor families with additional support. To the extent that Hong Kong SAR's labor market is segmented, with employment and wages driven by different factors, the setting of the minimum wage and choice of an adjustment scheme becomes even trickier. Ultimately, however, this is an empirical issue and as such we welcome the government's plans to supplement the available labor market and income databases so that these decisions can be well informed. Nonetheless, measurement of indicators such as aggregate wages, average productivity (output per worker), and unit labor cost growth (wage growth less productivity growth) should be based on available macroeconomic data to keep the exercise transparent.

In addition, our analysis of the effects of introducing a minimum wage in Hong Kong SAR could be extended along several dimensions. The set of mechanisms for adjusting the minimum wage over time could be augmented to encompass different adjustment frequencies, partial indexation, additional indexation variables, and asymmetric indexation. Furthermore, the sectoral impact of a minimum wage (with indexation) could be studied in a model with a highly segmented labor market, as could the introduction of a minimum wage complemented with direct income support for the working poor. These extensions remain objectives for future research. 


\section{Appendix I. Model DeVelopment, Estimation Procedure, AND ESTIMATION RESULTS}

Consider two open economies which are structurally isomorphic, except where stated otherwise. The domestic economy is small relative to the foreign economy. Each of these economies consists of households, firms and a government, which in turn consists of a monetary authority and a fiscal authority.

\section{The Household Sector}

There exists a continuum of households indexed by $i \in[0,1]$. Fraction $\varphi^{L}$ of households are of type $u$ and supply differentiated intermediate unskilled labor services. The remaining fraction $1-\varphi^{L}$ of households are of type $s$ and supply differentiated intermediate skilled labor services. Households of a given type $l \in\{u, s\}$ are otherwise identical.

\section{Consumption and Saving}

The representative infinitely lived household of a given type has preferences defined over consumption $C_{i, s}^{l}$ and labor supply $L_{i, s}^{l}$ represented by intertemporal utility function

$$
U_{i, t}^{l}=\mathrm{E}_{t} \sum_{s=t}^{\infty} \beta^{s-t} u\left(C_{i, s}^{l}, L_{i, s}^{l}\right)
$$

where subjective discount factor $\beta$ satisfies $0<\beta<1$. The intratemporal utility function is additively separable and represents external habit formation preferences in consumption and labor supply,

$$
u\left(C_{i, s}^{l}, L_{i, s}^{l}\right)=v_{s}^{C}\left[\frac{\left(C_{i, s}^{l}-\alpha^{C} C_{s-1}^{l}\right)^{1-1 / \sigma}}{1-1 / \sigma}-v^{L} \frac{\left(L_{i, s}^{l}-\alpha^{L} L_{s-1}^{l}\right)^{1+1 / \eta}}{1+1 / \eta}\right],
$$

where $0 \leq \alpha^{C}<1$ and $0 \leq \alpha^{L}<1$. This intratemporal utility function is strictly increasing with respect to consumption if and only if $v_{s}^{C}>0$, and given this parameter restriction is strictly decreasing with respect to labor supply if and only if $v^{L}>0$. Given these parameter restrictions, this intratemporal utility function is strictly concave if $\sigma>0$ and $\eta>0$.

The representative household of a given type enters period $s$ in possession of previously purchased domestic currency denominated bonds $B_{i, s}^{P, h, l}$ which yield interest at risk free rate $i_{s-1}$, and foreign currency denominated bonds $B_{i, s}^{P, f, l}$ which yield interest at risk free rate $i_{s-1}^{f}$. There exists a representative perfectly competitive financial intermediary which facilitates its foreign exchange transactions for consolidated fee $f_{s}$, generating revenues equal to its fixed costs. The representative household also holds a diversified portfolio of shares $\left\{x_{i, j, s}^{Y, l}\right\}_{j=0}^{1}$ in domestic intermediate good firms which pay dividends $\left\{\Pi_{j, s}^{Y}\right\}_{j=0}^{1}$, and diversified portfolios 
of shares $\left\{x_{i, k, s}^{T^{2}, l}\right\}_{k=0}^{1}$ in domestic intermediate good traders which pay dividends $\left\{\Pi_{k, s}^{T^{z}}\right\}_{k=0}^{1}$, where $T \in\{X, M\}$ and $z \in\{n, e\}$. It supplies differentiated intermediate labor service $L_{i, s}^{l}$, earning labor income at nominal wage $W_{i, s}^{l}$. Households pool their labor income, and the government levies a tax on pooled labor income at rate $\tau_{s}$. These sources of private wealth are summed in household dynamic budget constraint:

$$
\begin{aligned}
B_{i, s+1}^{P, h, l}+ & \mathcal{E}_{s} B_{i, s+1}^{P, f, l}+\int_{j=0}^{1} V_{j, s}^{Y} x_{i, j, s+1}^{Y, l} d j+\sum_{T^{z}} \int_{k=0}^{1} V_{k, s}^{T^{z}} x_{i, k, s+1}^{T^{2}, l} d k=\left(1+i_{s-1}\right) B_{i, s}^{P, h, l}+\mathcal{E}_{s}\left(1-f_{s}\right)\left(1+i_{s-1}^{f}\right) B_{i, s}^{P, f, l} \\
& +\int_{j=0}^{1}\left(\Pi_{j, s}^{Y}+V_{j, s}^{Y}\right) x_{i, j, s}^{Y, l} d j+\sum_{T^{z}} \int_{k=0}^{1}\left(\Pi_{k, s}^{T^{z}}+V_{k, s}^{T^{z}}\right) x_{i, k, s}^{T^{2}, l} d k+\left(1-\tau_{s}\right) \int_{h=0}^{1} W_{h, s}^{l} L_{h, s}^{l} d h-P_{s}^{C} C_{i, s}^{l} .
\end{aligned}
$$

According to this dynamic budget constraint, at the end of period $s$, the representative household purchases domestic bonds $B_{i, s+1}^{P, h, l}$, and foreign bonds $B_{i, s+1}^{P, f, l}$ at price $\mathcal{E}_{s}$. It also purchases a diversified portfolio of shares $\left\{x_{i, j, s+1}^{Y, l}\right\}_{j=0}^{1}$ in intermediate good firms at prices $\left\{V_{j, s}^{Y}\right\}_{j=0}^{1}$, and diversified portfolios of shares $\left\{x_{i, k, s+1}^{T^{T}, l}\right\}_{k=0}^{1}$ in intermediate good traders at prices $\left\{V_{k, s}^{T^{2}}\right\}_{k=0}^{1}$. Finally, the representative household purchases final consumption good $C_{i, s}^{l}$ at price $P_{s}^{C}$.

In period $t$, the representative household of a given type chooses state contingent sequences for consumption $\left\{C_{i, s}^{l}\right\}_{s=t}^{\infty}$, domestic bond holdings $\left\{B_{i, s+1}^{P, h, l}\right\}_{s=t}^{\infty}$, foreign bond holdings $\left\{B_{i, s+1}^{P, f, l}\right\}_{s=t}^{\infty}$, share holdings in intermediate good firms $\left\{\left\{x_{i, j, s+1}^{Y, l}\right\}_{j=0}^{1}\right\}_{s=t}^{\infty}$, and share holdings in intermediate good traders $\left\{\left\{x_{i, k, s+1}^{T^{2}, l}\right\}_{k=0}^{1}\right\}_{s=t}^{\infty}$ to maximize intertemporal utility function (3) subject to dynamic budget constraint (5) and terminal nonnegativity constraints $B_{i, T+1}^{P, h, l} \geq 0$, $B_{i, T+1}^{P, f, l} \geq 0, x_{i, j, T+1}^{Y, l} \geq 0$ and $x_{i, k, T+1}^{T^{z}, l} \geq 0$ for $T \rightarrow \infty$. In equilibrium, selected necessary first order conditions associated with this utility maximization problem may be stated as

$$
\begin{gathered}
u_{C}\left(C_{t}, L_{i, t}^{l}\right)=P_{t}^{C} \lambda_{t}, \\
\lambda_{t}=\beta\left(1+i_{t}\right) \mathrm{E}_{t} \lambda_{t+1}, \\
\mathcal{E}_{t} \lambda_{t}=\beta\left(1+i_{t}^{f}\right) \mathrm{E}_{t}\left(1-f_{t+1}\right) \mathcal{E}_{t+1} \lambda_{t+1}, \\
V_{j, t}^{Y} \lambda_{t}=\beta \mathrm{E}_{t}\left(\Pi_{j, t+1}^{Y}+V_{j, t+1}^{Y}\right) \lambda_{t+1}, \\
V_{k, t}^{T^{z}} \lambda_{t}=\beta \mathrm{E}_{t}\left(\Pi_{k, t+1}^{T^{z}}+V_{k, t+1}^{T^{z}}\right) \lambda_{t+1},
\end{gathered}
$$

where $\lambda_{i, s}^{l}$ denotes the Lagrange multiplier associated with the period $s$ household dynamic budget constraint. Provided that the intertemporal utility function is bounded and strictly concave, together with other necessary first order conditions, and transversality conditions 
derived from necessary complementary slackness conditions associated with the terminal nonnegativity constraints, these necessary first order conditions are sufficient for the unique utility maximizing state contingent intertemporal household allocation.

Combination of necessary first order conditions (6) and (7) yields intertemporal optimality condition

$$
u_{C}\left(C_{t}, L_{i, t}^{l}\right)=\beta \mathrm{E}_{t}\left(1+i_{t}\right) \frac{P_{t}^{C}}{P_{t+1}^{C}} u_{C}\left(C_{t+1}, L_{i, t+1}^{l}\right),
$$

which ensures that at a utility maximum, the representative household of a given type cannot benefit from feasible intertemporal consumption reallocations. Finally, combination of necessary first order conditions (6), (7) and (8) yields intratemporal optimality condition

$$
\mathrm{E}_{t} \frac{\beta u_{C}\left(C_{t+1}, L_{i, t+1}^{l}\right)}{u_{C}\left(C_{t}, L_{i, t}^{l}\right)} \frac{P_{t}^{C}}{P_{t+1}^{C}}\left(1+i_{t}\right)=\mathrm{E}_{t} \frac{\beta u_{C}\left(C_{t+1}, L_{i, t+1}^{l}\right)}{u_{C}\left(C_{t}, L_{i, t}^{l}\right)} \frac{P_{t}^{C}}{P_{t+1}^{C}} \frac{\mathcal{E}_{t+1}}{\mathcal{E}_{t}}\left(1-f_{t+1}\right)\left(1+i_{t}^{f}\right),
$$

which equates the expected present values of the gross real returns on domestic and foreign bonds.

\section{Labor Supply and Wage Setting}

There exist a large number of perfectly competitive firms which combine the final unskilled labor service $L_{t}^{u}$ having productivity coefficient $A_{t}^{u}$ with the final skilled labor service $L_{t}^{s}$ having productivity coefficient $A_{t}^{s}$ to produce a final labor service $L_{t}$ having productivity coefficient $A_{t}$ according to constant elasticity of substitution production function

$$
A_{t} L_{t}=\left[\left(\varphi^{L}\right)^{\frac{1}{\vartheta}}\left(A_{t}^{u} L_{t}^{u}\right)^{\frac{\vartheta-1}{\vartheta}}+\left(1-\varphi^{L}\right)^{\frac{1}{\vartheta}}\left(A_{t}^{s} L_{t}^{s}\right)^{\frac{\vartheta-1}{\vartheta}}\right]^{\frac{\vartheta}{\vartheta-1}}
$$

where $0<\varphi^{L} \leq 1, \vartheta>0$ and $A_{t}^{s} \geq A_{t} \geq A_{t}^{u}>0$. The representative final labor service firm maximizes profits derived from production of the final labor service, with respect to inputs of the final unskilled and skilled labor services, implying final unskilled and skilled effective labor service demand functions:

$$
A_{t}^{u} L_{t}^{u}=\varphi^{L}\left(\frac{W_{t}^{u} / A_{t}^{u}}{W_{t} / A_{t}}\right)^{-\vartheta} A_{t} L_{t}
$$




$$
A_{t}^{s} L_{t}^{s}=\left(1-\varphi^{L}\right)\left(\frac{W_{t}^{s} / A_{t}^{s}}{W_{t} / A_{t}}\right)^{-\vartheta} A_{t} L_{t}
$$

Since the production function exhibits constant returns to scale, in equilibrium the representative final labor service firm earns zero profit, implying aggregate effective wage index:

$$
\frac{W_{t}}{A_{t}}=\left[\varphi^{L}\left(\frac{W_{t}^{u}}{A_{t}^{u}}\right)^{1-\vartheta}+\left(1-\varphi^{L}\right)\left(\frac{W_{t}^{s}}{A_{t}^{s}}\right)^{1-\vartheta}\right]^{\frac{1}{1-\vartheta}}
$$

This aggregate effective wage index equals the minimum cost of producing one unit of the final effective labor service, given the effective wages for the final unskilled and skilled labor services.

There exist a large number of perfectly competitive firms which combine differentiated intermediate labor services $L_{i, t}^{l}$ supplied by households of a given type in a monopolistically competitive labor market to produce final labor service $L_{t}^{l}$ according to constant elasticity of substitution production function

$$
L_{t}^{l}=\left[\int_{i=0}^{1}\left(L_{i, t}^{l}\right)^{\frac{\theta_{t}^{L}-1}{\theta_{t}^{L}}} d i\right]^{\frac{\theta_{t}^{L}}{\theta_{t}^{L}-1}}
$$

where $\theta_{t}^{L}>1$. The representative final labor service firm maximizes profits derived from production of the final labor service, with respect to inputs of intermediate labor services, implying intermediate labor service demand functions:

$$
L_{i, t}^{l}=\left(\frac{W_{i, t}^{l}}{W_{t}^{l}}\right)^{-\theta_{t}^{L}} L_{t}^{l}
$$

Since the production function exhibits constant returns to scale, in equilibrium the representative final labor service firm earns zero profit, implying aggregate wage index:

$$
W_{t}^{l}=\left[\int_{i=0}^{1}\left(W_{i, t}^{l}\right)^{1-\theta_{t}^{L}} d i\right]^{\frac{1}{1-\theta_{t}^{L}}}
$$


As the wage elasticity of demand for intermediate labor services $\theta_{t}^{L}$ increases, they become closer substitutes, and individual households have less market power.

In an extension of the model of nominal wage rigidity proposed by Erceg, Henderson and Levin (2000) along the lines of Smets and Wouters (2003), each period a randomly selected fraction $1-\omega^{L_{l}}$ of households of a given type adjust their wage optimally. The remaining fraction $\omega^{L_{l}}$ of households adjust their wage according to indexation rule:

$$
W_{i, t}^{l}=\frac{W_{t}^{I_{l}}}{W_{t-1}^{I_{l}}} W_{i, t-1}^{l} .
$$

The indexed wage for households of a given type $W_{t}^{I_{I}}$ is adjusted to account for past aggregate wage inflation, consumption price inflation and average labor productivity growth,

$$
W_{t}^{I_{l}}=\left(\frac{W_{t-1}}{W_{t-2}}\right)^{\nu_{l, W}}\left(\frac{P_{t-1}^{C}}{P_{t-2}^{C}}\right)^{\gamma_{l, P},}\left(\frac{y_{t-1}}{y_{t-2}}\right)^{\gamma_{l, y}^{L_{l}, y}} W_{t-1}^{I_{l}},
$$

where $0 \leq \gamma^{L_{1}, W} \leq 1,0 \leq \gamma^{L_{l}, P} \leq 1$ and $0 \leq \gamma^{L_{l}, Y / L} \leq 1$. Under this specification, although households adjust their wage every period, they infrequently adjust their wage optimally, and the interval between optimal wage adjustments is a random variable.

If the representative household of a given type can adjust its wage optimally in period $t$, then it does so to maximize intertemporal utility function (3) subject to dynamic budget constraint (5), intermediate labor service demand function (18), and the assumed form of nominal wage rigidity. Since all households of a given type that adjust their wage optimally in period $t$ solve an identical utility maximization problem, in equilibrium they all choose a common wage $W_{t}^{l, *}$ given by necessary first order condition:

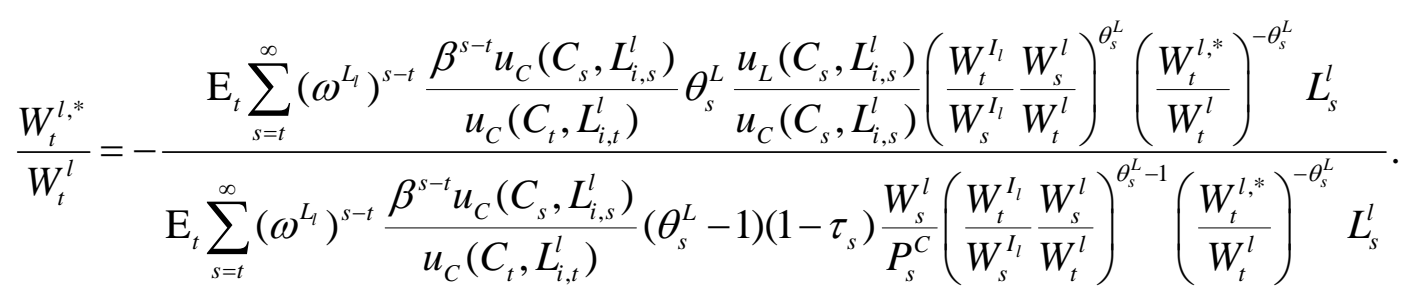

This necessary first order condition equates the expected present value of the consumption benefit generated by an additional unit of labor supply to the expected present value of its leisure cost. Aggregate wage index (19) equals an average of the wage set by the fraction $1-\omega^{L_{l}}$ of households of a given type that adjust their wage optimally in period $t$, and the average of the wages set by the remaining fraction $\omega^{L_{l}}$ of households that adjust their wage according to indexation rule (20): 


$$
W_{t}^{l}=\left\{\left(1-\omega^{L_{l}}\right)\left(W_{t}^{l, *}\right)^{1-\theta_{t}^{L}}+\omega^{L_{l}}\left[\frac{W_{t}^{I_{l}}}{W_{t-1}^{I_{l}}} W_{t-1}^{l}\right]^{1-\theta_{t}^{L}}\right\}^{\frac{1}{1-\theta_{t}^{L}}}
$$

Since those households of a given type able to adjust their wage optimally in period $t$ are selected randomly from among all households of that type, the average wage set by the remaining households equals the value of the aggregate wage index that prevailed during period $t-1$, rescaled to account for past wage inflation, consumption price inflation and labor productivity growth.

\section{The Production Sector}

There exists a continuum of intermediate good firms indexed by $j \in[0,1]$. Intermediate good firms supply differentiated intermediate output goods, but are otherwise identical. Entry into and exit from the monopolistically competitive intermediate output good sector is prohibited.

\section{Labor Demand and Investment}

The representative intermediate good firm sells shares $\left\{x_{i, j, t+1}^{Y, l}\right\}_{i=0}^{1}$ to domestic households at price $V_{j, t}^{Y}$. Recursive forward substitution for $V_{j, t+s}^{Y}$ with $s>0$ in necessary first order condition (9) applying the law of iterated expectations reveals that the post-dividend stock market value of the representative intermediate good firm equals the expected present value of future dividend payments:

$$
V_{j, t}^{Y}=\mathrm{E}_{t} \sum_{s=t+1}^{\infty} \frac{\beta^{s-t} \lambda_{s}}{\lambda_{t}} \Pi_{j, s}^{Y} .
$$

Acting in the interests of its shareholders, the representative intermediate good firm maximizes its pre-dividend stock market value, equal to the expected present value of current and future dividend payments:

$$
\Pi_{j, t}^{Y}+V_{j, t}^{Y}=\mathrm{E}_{t} \sum_{s=t}^{\infty} \frac{\beta^{s-t} \lambda_{s}}{\lambda_{t}} \Pi_{j, s}^{Y} .
$$

The derivation of result (24) imposes a transversality condition which rules out self-fulfilling speculative asset price bubbles.

Shares entitle households to dividend payments equal to net profits $\Pi_{j, s}^{Y}$, defined as after tax earnings less investment expenditures:

$$
\Pi_{j, s}^{Y}=\left(1-\tau_{s}\right)\left(P_{j, s}^{Y} Y_{j, s}-W_{s} L_{j, s}\right)-P_{s}^{I} I_{s}
$$


Earnings are defined as revenues derived from sales of differentiated intermediate output good $Y_{j, s}$ at price $P_{j, s}^{Y}$ less expenditures on final labor service $L_{j, s}$. The government levies a tax on earnings at rate $\tau_{s}$.

The representative intermediate good firm utilizes capital $K_{s}$ at rate $u_{j, s}$ and rents final labor service $L_{j, s}$ given productivity coefficient $A_{s}$ to produce differentiated intermediate output good $Y_{j, s}$ according to constant elasticity of substitution production function

$$
\mathcal{F}\left(u_{j, s} K_{s}, A_{s} L_{j, s}\right)=\left[\left(\varphi^{K}\right)^{\frac{1}{\vartheta}}\left(u_{j, s} K_{s}\right)^{\frac{\vartheta-1}{\vartheta}}+\left(1-\varphi^{K}\right)^{\frac{1}{\vartheta}}\left(A_{s} L_{j, s}\right)^{\frac{\vartheta-1}{\vartheta}}\right]^{\frac{\vartheta}{\vartheta-1}},
$$

where $0<\varphi^{K}<1, \vartheta>0$ and $A_{s}>0$. This constant elasticity of substitution production function exhibits constant returns to scale.

In utilizing capital to produce output, the representative intermediate good firm incurs a cost $\mathcal{G}\left(u_{j, s}, K_{s}\right)$ denominated in terms of output:

$$
Y_{j, s}=\mathcal{F}\left(u_{j, s} K_{s}, A_{s} L_{j, s}\right)-\mathcal{G}\left(u_{j, s}, K_{s}\right)
$$

Following Christiano, Eichenbaum and Evans (2005), this capital utilization cost is increasing in the rate of capital utilization at an increasing rate,

$$
\mathcal{G}\left(u_{j, s}, K_{s}\right)=\mu\left[e^{\kappa\left(u_{j, s}-1\right)}-1\right] K_{s},
$$

where $\mu>0$ and $\kappa>0 .^{2}$ In deterministic steady state equilibrium, the rate of capital utilization is normalized to one, and the cost of utilizing capital equals zero.

Capital is endogenous but not firm-specific, and the representative intermediate good firm enters period $s$ with access to previously accumulated capital stock $K_{s}$, which subsequently evolves according to accumulation function

$$
K_{s+1}=(1-\delta) K_{s}+\mathcal{H}\left(I_{s}, I_{s-1}\right),
$$

\footnotetext{
${ }^{2}$ Partial differentiation of this capital utilization cost function yields $\mathcal{G}_{u}\left(u_{j, s}, K_{s}\right)=\mu \kappa e^{\kappa\left(u_{j, s}-1\right)} K_{s}>0$ and $\mathcal{G}_{u, u}\left(u_{j, s}, K_{s}\right)=\mu \kappa^{2} e^{\kappa\left(u_{j, s}-1\right)} K_{s}>0$.
} 
where depreciation rate parameter $\delta$ satisfies $0 \leq \delta \leq 1$. Following Christiano, Eichenbaum and Evans (2005), effective investment function $\mathcal{H}\left(I_{s}, I_{s-1}\right)$ incorporates convex adjustment costs,

$$
\mathcal{H}\left(I_{s}, I_{s-1}\right)=v_{s}^{I}\left[1-\frac{\chi}{2}\left(\frac{I_{s}-I_{s-1}}{I_{s-1}}\right)^{2}\right] I_{s},
$$

where $\chi>0$ and $v_{s}^{I}>0$. In deterministic steady state equilibrium, these adjustment costs equal zero, and effective investment equals actual investment.

In period $t$, the representative intermediate good firm chooses state contingent sequences for employment $\left\{L_{i, s}\right\}_{s=t}^{\infty}$, capital utilization $\left\{u_{j, s}\right\}_{s=t}^{\infty}$, investment $\left\{I_{s}\right\}_{s=t}^{\infty}$, and the capital stock $\left\{K_{s+1}\right\}_{s=t}^{\infty}$ to maximize pre-dividend stock market value (25) subject to net production function (28), capital accumulation function (30), and terminal nonnegativity constraint $K_{T+1} \geq 0$ for $T \rightarrow \infty$. In equilibrium, demand for the final labor service satisfies necessary first order condition

$$
\mathcal{F}_{A L}\left(u_{j, t} K_{t}, A_{t} L_{j, t}\right) \Phi_{j, t}=\left(1-\tau_{t}\right) \frac{W_{t}}{P_{t}^{Y} A_{t}},
$$

where $P_{s}^{Y} \Phi_{j, s}$ denotes the Lagrange multiplier associated with the period $s$ production technology constraint. This necessary first order condition equates real marginal cost $\Phi_{j, t}$ to the ratio of the after tax real wage to the marginal product of labor. In equilibrium, the rate of capital utilization satisfies necessary first order condition

$$
\mathcal{F}_{u K}\left(u_{j, t} K_{t}, A_{t} L_{j, t}\right)=\frac{\mathcal{G}_{u}\left(u_{j, t}, K_{t}\right)}{K_{t}},
$$

which equates the marginal product of utilized capital to its marginal cost. In equilibrium, demand for the final investment good satisfies necessary first order condition

$$
Q_{t} \mathcal{H}_{1}\left(I_{t}, I_{t-1}\right)+\mathrm{E}_{t} \frac{\beta \lambda_{t+1}}{\lambda_{t}} Q_{t+1} \mathcal{H}_{2}\left(I_{t+1}, I_{t}\right)=P_{t}^{I},
$$

which equates the expected present value of an additional unit of investment in capital to its price, where $Q_{j, s}$ denotes the Lagrange multiplier associated with the period $s$ capital accumulation function. In equilibrium, this shadow price of capital satisfies necessary first order condition 


$$
Q_{t}=\mathrm{E}_{t} \frac{\beta \lambda_{t+1}}{\lambda_{t}}\left\{P_{t+1}^{Y} \Phi_{j, t+1}\left[u_{j, t+1} \mathcal{F}_{u K}\left(u_{j, t+1} K_{t+1}, A_{t+1} L_{j, t+1}\right)-\mathcal{G}_{K}\left(u_{j, t+1}, K_{t+1}\right)\right]+(1-\delta) Q_{t+1}\right\},
$$

which equates it to the expected present value of the sum of the future marginal cost of capital, and the future shadow price of capital net of depreciation. Provided that the pre-dividend stock market value of the representative intermediate good firm is bounded and strictly concave, together with other necessary first order conditions, and a transversality condition derived from the necessary complementary slackness condition associated with the terminal nonnegativity constraint, these necessary first order conditions are sufficient for the unique value maximizing state contingent intertemporal firm allocation.

\section{Output Supply and Price Setting}

There exist a large number of perfectly competitive firms which combine differentiated intermediate output goods $Y_{j, t}$ supplied by intermediate good firms to produce final output good $Y_{t}$ according to constant elasticity of substitution production function

$$
Y_{t}=\left[\int_{j=0}^{1}\left(Y_{j, t}\right)^{\frac{\theta_{t}^{Y}-1}{\theta_{t}^{Y}}} d j\right]^{\frac{\theta_{t}^{Y}}{\theta_{t}^{Y}-1}},
$$

where $\theta_{t}^{Y}>1$. The representative final output good firm maximizes profits derived from production of the final output good, with respect to inputs of intermediate output goods, implying intermediate output good demand functions:

$$
Y_{j, t}=\left(\frac{P_{j, t}^{Y}}{P_{t}^{Y}}\right)^{-\theta_{t}^{Y}} Y_{t}
$$

Since the production function exhibits constant returns to scale, in equilibrium the representative final output good firm earns zero profit, implying aggregate output price index:

$$
P_{t}^{Y}=\left[\int_{j=0}^{1}\left(P_{j, t}^{Y}\right)^{1-\theta_{t}^{Y}} d j\right]^{\frac{1}{1-\theta_{t}^{Y}}}
$$

As the price elasticity of demand for intermediate output goods $\theta_{t}^{Y}$ increases, they become closer substitutes, and individual intermediate good firms have less market power. 
In an extension of the model of nominal output price rigidity proposed by Calvo (1983) along the lines of Smets and Wouters (2003), each period a randomly selected fraction $1-\omega^{Y}$ of intermediate good firms adjust their price optimally. The remaining fraction $\omega^{Y}$ of intermediate good firms adjust their price to account for past aggregate output price inflation according to partial indexation rule

$$
P_{j, t}^{Y}=\left(\frac{P_{t-1}^{Y}}{P_{t-2}^{Y}}\right)^{\gamma^{Y}} P_{j, t-1}^{Y},
$$

where $0 \leq \gamma^{Y} \leq 1$. Under this specification, optimal price adjustment opportunities arrive randomly, and the interval between optimal price adjustments is a random variable.

If the representative intermediate good firm can adjust its price optimally in period $t$, then it does so to maximize pre-dividend stock market value (25) subject to net production function (28), capital accumulation function (30), intermediate output good demand function (37), and the assumed form of nominal output price rigidity. Since all intermediate good firms that adjust their price optimally in period $t$ solve an identical value maximization problem, in equilibrium they all choose a common price $P_{t}^{Y, *}$ given by necessary first order condition:

$$
\frac{P_{t}^{Y, *}}{P_{t}^{Y}}=\frac{\mathrm{E}_{t} \sum_{s=t}^{\infty}\left(\omega^{Y}\right)^{s-t} \frac{\beta^{s-t} \lambda_{s}}{\lambda_{t}} \theta_{s}^{Y} \Phi_{j, s}\left[\left(\frac{P_{t-1}^{Y}}{P_{s-1}^{Y}}\right)^{\gamma^{Y}} \frac{P_{s}^{Y}}{P_{t}^{Y}}\right]^{\theta_{s}^{Y}}\left(\frac{P_{t}^{Y, *}}{P_{t}^{Y}}\right)^{-\theta_{s}^{Y}} P_{s}^{Y} Y_{s}}{\mathrm{E}_{t} \sum_{s=t}^{\infty}\left(\omega^{Y}\right)^{s-t} \frac{\beta^{s-t} \lambda_{s}}{\lambda_{t}}\left(\theta_{s}^{Y}-1\right)\left(1-\tau_{s}\right)\left[\left(\frac{P_{t-1}^{Y}}{P_{s-1}^{Y}}\right)^{\gamma^{Y}} \frac{P_{s}^{Y}}{P_{t}^{Y}}\right]^{\theta_{s}^{Y}-1}\left(\frac{P_{t}^{Y, *}}{P_{t}^{Y}}\right)^{-\theta_{s}^{Y}} P_{s}^{Y} Y_{s}} .
$$

This necessary first order condition equates the expected present value of the after tax revenue benefit generated by an additional unit of output supply to the expected present value of its production cost. Aggregate output price index (38) equals an average of the price set by the fraction $1-\omega^{Y}$ of intermediate good firms that adjust their price optimally in period $t$, and the average of the prices set by the remaining fraction $\omega^{Y}$ of intermediate good firms that adjust their price according to partial indexation rule (39):

$$
P_{t}^{Y}=\left\{\left(1-\omega^{Y}\right)\left(P_{t}^{Y, *}\right)^{1-\theta_{t}^{Y}}+\omega^{Y}\left[\left(\frac{P_{t-1}^{Y}}{P_{t-2}^{Y}}\right)^{Y^{Y}} P_{t-1}^{Y}\right]^{1-\theta_{t}^{Y}}\right\}^{\frac{1}{1-\theta_{t}^{Y}}} .
$$

Since those intermediate good firms able to adjust their price optimally in period $t$ are selected randomly from among all intermediate good firms, the average price set by the 
remaining intermediate good firms equals the value of the aggregate output price index that prevailed during period $t-1$, rescaled to account for past output price inflation.

\section{The Import and Export Sectors}

The domestic economy imports the foreign final output good, which it processes for purposes of absorption and exportation. The foreign economy imports the domestic final output and processed foreign final output goods, which it processes for purposes of absorption.

There exist a large number of perfectly competitive firms which combine the final nonentrepôt trade good $T_{t}^{n}$ with the final entrepôt trade good $T_{t}^{e}$ to produce final trade good $T_{t}$ according to constant elasticity of substitution production function

$$
T_{t}=\left[\left(\phi^{T}\right)^{\frac{1}{\psi^{T}}}\left(T_{t}^{n}\right)^{\frac{\psi^{T}-1}{\psi^{T}}}+\left(1-\phi^{T}\right)^{\frac{1}{\psi^{T}}}\left(T_{t}^{e}\right)^{\frac{\psi^{T}-1}{\psi^{T}}}\right]^{\frac{\psi^{T}}{\psi^{T}-1}},
$$

where $0<\phi^{T}<1$ and $\psi^{T}>1$. The representative final trade good firm maximizes profits derived from production of the final trade good, with respect to inputs of the final nonentrepôt and entrepôt trade goods, implying final nonentrepôt and entrepôt trade good demand functions:

$$
\begin{gathered}
T_{t}^{n}=\phi^{T}\left(\frac{P_{t}^{T^{n}}}{P_{t}^{T}}\right)^{-\psi^{T}} T_{t}, \\
T_{t}^{e}=\left(1-\phi^{T}\right)\left(\frac{P_{t}^{T^{e}}}{P_{t}^{T}}\right)^{-\psi^{T}} T_{t} .
\end{gathered}
$$

Since the production function exhibits constant returns to scale, in equilibrium the representative final trade good firm earns zero profit, implying aggregate trade price index:

$$
P_{t}^{T}=\left[\phi^{T}\left(P_{t}^{T^{n}}\right)^{1-\psi^{T}}+\left(1-\phi^{T}\right)\left(P_{t}^{T^{e}}\right)^{1-\psi^{T}}\right]^{\frac{1}{1-\psi^{T}}} .
$$

This aggregate trade price index equals the minimum cost of producing one unit of the final trade good, given the prices of the final nonentrepôt and entrepôt trade goods. 


\section{The Real Exchange Rate and the Terms of Trade}

The real exchange rate and the terms of trade are measures of the external price competitiveness of the output market. Define the real exchange rate,

$$
\mathcal{Q}_{s}=\frac{\mathcal{E}_{s} P_{s}^{Y, f}}{P_{s}^{Y}},
$$

which measures the price of foreign output in terms of domestic output. Also define the terms of trade,

$$
\mathcal{T}_{s}^{z}=\frac{P_{s}^{M^{2}}}{P_{s}^{X^{2}}},
$$

which measures the price of imports in terms of exports. The domestic currency price of nonentrepôt exports satisfies $P_{s}^{X^{n}}=P_{s}^{Y}$.

There exist a large number of perfectly competitive firms which combine the final output good $Z_{t}^{h} \in\left\{C_{t}^{h}, I_{t}^{h}, G_{t}^{h}\right\}$ with the final nonentrepôt import good $Z_{t}^{f} \in\left\{C_{t}^{f}, I_{t}^{f}, G_{t}^{f}\right\}$ to produce final domestic good $Z_{t} \in\left\{C_{t}, I_{t}, G_{t}\right\}$ according to constant elasticity of substitution production function

$$
Z_{t}=\left[\left(\phi^{Z}\right)^{\frac{1}{\psi}}\left(Z_{t}^{h}\right)^{\frac{\psi-1}{\psi}}+\left(1-\phi^{Z}\right)^{\frac{1}{\psi}}\left(v_{t}^{M} Z_{t}^{f}\right)^{\frac{\psi-1}{\psi}}\right]^{\frac{\psi}{\psi-1}},
$$

where $0<\phi^{Z}<1, \psi>1$ and $v_{t}^{M}>0$. The representative final domestic good firm maximizes profits derived from production of the final domestic good, with respect to inputs of the final output and nonentrepôt import goods, implying final output and nonentrepôt import good demand functions:

$$
\begin{gathered}
Z_{t}^{h}=\phi^{Z}\left(\frac{P_{t}^{Y}}{P_{t}^{Z}}\right)^{-\psi} Z_{t}, \\
Z_{t}^{f}=\left(1-\phi^{Z}\right)\left(\frac{P_{t}^{M^{n}}}{v_{t}^{M} P_{t}^{Z}}\right)^{-\psi} \frac{Z_{t}}{v_{t}^{M}} .
\end{gathered}
$$

Since the production function exhibits constant returns to scale, in equilibrium the representative final domestic good firm earns zero profit, implying aggregate domestic price index: 


$$
P_{t}^{Z}=\left[\phi^{Z}\left(P_{t}^{Y}\right)^{1-\psi}+\left(1-\phi^{Z}\right)\left(\frac{P_{t}^{M^{n}}}{v_{t}^{M}}\right)^{1-\psi}\right]^{\frac{1}{1-\psi}}
$$

Combination of this aggregate domestic price index with final output and nonentrepôt import good demand functions (49) and (50) yields:

$$
\begin{gathered}
Z_{t}^{h}=\phi^{Z}\left[\phi^{Z}+\left(1-\phi^{Z}\right)\left(\frac{\mathcal{T}_{t}^{n}}{v_{t}^{M}}\right)^{1-\psi}\right]^{\frac{\psi}{1-\psi}} Z_{t}, \\
Z_{t}^{f}=\left(1-\phi^{Z}\right)\left[\left(1-\phi^{Z}\right)+\phi^{Z}\left(\frac{\mathcal{T}_{t}^{n}}{v_{t}^{M}}\right)^{\psi-1}\right]^{\frac{\psi}{1-\psi}} \frac{Z_{t}}{v_{t}^{M}} .
\end{gathered}
$$

These demand functions for the final output and nonentrepôt import goods are directly proportional to final domestic good demand, with a proportionality coefficient that varies with the terms of trade.

\section{Import Supply, Export Supply and Price Setting}

There exist a large number of perfectly competitive firms which combine differentiated intermediate trade goods $T_{k, t}^{z}$ supplied by intermediate good traders to produce final trade good $T_{t}^{z}$ according to constant elasticity of substitution production function

$$
T_{t}^{Z}=\left[\int_{k=0}^{1}\left(T_{k, t}^{z}\right)^{\frac{\theta^{T}-1}{\theta^{T}}} d k\right]^{\frac{\theta^{T}}{\theta^{T}-1}}
$$

where $\theta^{T}>1$. The representative final trade good firm maximizes profits derived from production of the final trade good, with respect to inputs of intermediate trade goods, implying intermediate trade good demand functions:

$$
T_{k, t}^{z}=\left(\frac{P_{k, t}^{T^{z}}}{P_{t}^{T^{2}}}\right)^{-\theta^{T}} T_{t}^{z} .
$$

Since the production function exhibits constant returns to scale, in equilibrium the representative final trade good firm earns zero profit, implying aggregate trade price index: 


$$
P_{t}^{T^{z}}=\left[\int_{k=0}^{1}\left(P_{k, t}^{T^{z}}\right)^{1-\theta^{T}} d k\right]^{\frac{1}{1-\theta^{T}}}
$$

As the price elasticity of demand for intermediate trade goods $\theta^{T}$ increases, they become closer substitutes, and individual intermediate good traders have less market power.

There exist continuums of intermediate nonentrepôt and entrepôt good traders indexed by $k \in[0,1]$. Intermediate good traders supply differentiated intermediate trade goods, but are otherwise identical. Entry into and exit from the monopolistically competitive intermediate trade good sectors is prohibited.

The representative intermediate good trader sells shares $\left\{x_{i, k, t+1}^{T^{z}, l}\right\}_{i=0}^{1}$ to domestic households at price $V_{k, t}^{T^{z}}$. Recursive forward substitution for $V_{k, t+s}^{T^{z}}$ with $s>0$ in necessary first order condition (10) applying the law of iterated expectations reveals that the post-dividend stock market value of the representative intermediate good trader equals the expected present value of future dividend payments:

$$
V_{k, t}^{T^{z}}=\mathrm{E}_{t} \sum_{s=t+1}^{\infty} \frac{\beta^{s-t} \lambda_{s}}{\lambda_{t}} \Pi_{k, s}^{T^{2}} .
$$

Acting in the interests of its shareholders, the representative intermediate good trader maximizes its pre-dividend stock market value, equal to the expected present value of current and future dividend payments:

$$
\Pi_{k, t}^{T^{z}}+V_{k, t}^{T^{2}}=\mathrm{E}_{t} \sum_{s=t}^{\infty} \frac{\beta^{s-t} \lambda_{s}}{\lambda_{t}} \Pi_{k, s}^{T^{2}} .
$$

The derivation of result (57) imposes a transversality condition which rules out self-fulfilling speculative asset price bubbles.

Shares entitle households to dividend payments equal to gross profits $\Pi_{k, s}^{T^{z}}$, defined as earnings less fixed costs $F_{s}^{T^{2}}$ :

$$
\begin{gathered}
\Pi_{k, s}^{X^{e}}=P_{k, s}^{X^{e}} X_{k, s}^{e}-P_{s}^{M^{e}} M_{k, s}^{e}, \\
\Pi_{k, s}^{M^{z}}=P_{k, s}^{M^{z}} M_{k, s}^{z}-\mathcal{E}_{s} P_{s}^{Y, f} M_{k, s}^{z}-F_{s}^{M^{z}} .
\end{gathered}
$$


Earnings are defined as revenues derived from sales of differentiated intermediate trade good $T_{k, s}^{z}$ at price $P_{k, s}^{T^{z}}$ less purchases of domestic final entrepôt import good $M_{k, s}^{e}$ at price $P_{s}^{M^{e}}$ or foreign final output good $M_{k, s}^{z}$ at price $\mathcal{E}_{s} P_{s}^{Y, f}$. Where applicable, fixed costs equal average earnings, implying zero average gross profits.

In an extension of the model of nominal import price rigidity proposed by Monacelli (2005) along the lines of Smets and Wouters (2003), each period a randomly selected fraction $1-\omega^{T}$ of intermediate good traders adjust their price optimally. The remaining fraction $\omega^{T}$ of intermediate good traders adjust their price to account for past aggregate trade price inflation according to partial indexation rule

$$
P_{k, t}^{T^{z}}=\left(\frac{P_{t-1}^{T^{z}}}{P_{t-2}^{T^{z}}}\right)^{\gamma^{T}} P_{k, t-1}^{T^{z}},
$$

where $0 \leq \gamma^{T} \leq 1$. Under this specification, the probability that an intermediate good trader has adjusted its price optimally is time dependent but state independent.

If the representative intermediate good trader can adjust its price optimally in period $t$, then it does so to maximize pre-dividend stock market value (58) subject to intermediate trade good demand function (55), and the assumed form of nominal trade price rigidity. Since all intermediate good traders that adjust their price optimally in period $t$ solve an identical value maximization problem, in equilibrium they all choose a common price $P_{t}^{T^{z} \text {, }}$ given by necessary first order condition

$$
\frac{P_{t}^{T^{z}, *}}{P_{t}^{T^{z}}}=\left(\frac{\theta^{T}}{\theta^{T}-1}\right) \frac{\mathrm{E}_{t} \sum_{s=t}^{\infty}\left(\omega^{T}\right)^{s-t} \frac{\beta^{s-t} \lambda_{s}}{\lambda_{t}} \Psi_{s}^{T^{z}}\left[\left(\frac{P_{t-1}^{T^{z}}}{P_{s-1}^{T^{z}}}\right)^{\gamma^{T}} \frac{P_{s}^{T^{z}}}{P_{t}^{T^{z}}}\right]^{\theta^{T}} P_{s}^{T^{z}} T_{s}^{z}}{\mathrm{E}_{t} \sum_{s=t}^{\infty}\left(\omega^{T}\right)^{s-t} \frac{\beta^{s-t} \lambda_{s}}{\lambda_{t}}\left[\left(\frac{P_{t-1}^{T^{z}}}{P_{s-1}^{T^{z}}}\right)^{\gamma^{T}} \frac{P_{s}^{T^{z}}}{P_{t}^{T^{z}}}\right]^{\theta^{T}-1} P_{s}^{T^{z}} T_{s}^{z}},
$$

where $\Psi_{s}^{X^{e}}=P_{s}^{M^{e}} / P_{s}^{X^{e}}$ and $\Psi_{s}^{M^{2}}=\mathcal{E}_{s} P_{s}^{Y, f} / P_{s}^{M^{2}}$ measure real marginal costs. This necessary first order condition equates the expected present value of the revenue benefit generated by an additional unit of trade supply to the expected present value of its production cost. Aggregate trade price index (56) equals an average of the price set by the fraction $1-\omega^{T}$ of intermediate good traders that adjust their price optimally in period $t$, and the average of the prices set by the remaining fraction $\omega^{T}$ of intermediate good traders that adjust their price according to partial indexation rule (61): 


$$
P_{t}^{T^{2}}=\left\{\left(1-\omega^{T}\right)\left(P_{t}^{T^{z}, *}\right)^{1-\theta^{T}}+\omega^{T}\left[\left(\frac{P_{t-1}^{T^{2}}}{P_{t-2}^{T^{2}}}\right)^{\gamma^{T}} P_{t-1}^{T^{2}}\right]^{1-\theta^{T}}\right\}^{\frac{1}{1-\theta^{T}}}
$$

Since those intermediate good traders able to adjust their price optimally in period $t$ are selected randomly from among all intermediate good traders, the average price set by the remaining intermediate good traders equals the value of the aggregate trade price index that prevailed during period $t-1$, rescaled to account for past trade price inflation.

\section{Monetary and Fiscal Policy}

The government consists of a monetary authority and a fiscal authority. The monetary authority implements monetary policy, while the fiscal authority implements fiscal policy.

\section{The Monetary Authority}

The monetary authority implements monetary policy through control of the short term nominal interest rate according to a monetary policy rule exhibiting partial adjustment dynamics of the form

$$
\begin{aligned}
i_{t}-\bar{i}_{t}= & \rho_{i}\left(i_{t-1}-\bar{i}_{t-1}\right) \\
& +\left(1-\rho_{i}\right)\left[\xi^{\pi}\left(\pi_{t}^{C}-\bar{\pi}_{t}^{C}\right)+\xi^{Y}\left(\ln Y_{t}-\ln \bar{Y}_{t}\right)+\xi^{i}\left(i_{t}^{f}-\bar{i}_{t}^{f}\right)+\xi^{\mathcal{E}}\left(\ln \mathcal{E}_{t}-\ln \overline{\mathcal{E}}_{t}\right)\right]+v_{t}^{i},
\end{aligned}
$$

where $0 \leq \rho_{i}<1, \xi^{\pi} \geq 0, \xi^{Y} \geq 0, \xi^{i} \geq 0$ and $\xi^{\mathcal{E}} \geq 0$. As specified, the deviation of the nominal interest rate from its deterministic steady state equilibrium value depends on an average of its past deviation and its desired deviation, which in turn depends on the contemporaneous deviations of consumption price inflation, output, the foreign nominal interest rate, and the nominal exchange rate from their deterministic steady state equilibrium values. The domestic monetary authority implements a fixed exchange rate regime, represented by $\rho_{i}=0, \xi^{\pi}=0, \xi^{Y}=0, \xi^{i}=1$ and $\xi^{\mathcal{E}}>0$. The foreign monetary authority implements a flexible inflation targeting regime, represented by $0 \leq \rho_{i, f}<1, \xi^{\pi, f}>1$, $\xi^{Y, f} \geq 0, \xi^{i, f}=0$ and $\xi^{\mathcal{E}, f}=0$. Transitory departures from this monetary policy rule are captured by serially uncorrelated monetary policy shock $v_{t}^{i}$.

\section{The Fiscal Authority}

The fiscal authority implements fiscal policy through control of nominal government consumption and the tax rate applicable to the pooled labor income of households and the earnings of intermediate good firms. In equilibrium, this distortionary tax collection framework corresponds to proportional output taxation. 
The ratio of nominal government consumption to nominal output satisfies a fiscal expenditure rule exhibiting partial adjustment dynamics of the form

$$
\ln \frac{P_{t}^{G} G_{t}}{P_{t}^{Y} Y_{t}}-\ln \frac{\bar{P}_{t}^{G} \bar{G}_{t}}{\bar{P}_{t}^{Y} \bar{Y}_{t}}=\rho_{G}\left(\ln \frac{P_{t-1}^{G} G_{t-1}}{P_{t-1}^{Y} Y_{t-1}}-\ln \frac{\bar{P}_{t-1}^{G} \bar{G}_{t-1}}{\bar{P}_{t-1}^{Y} \bar{Y}_{t-1}}\right)+\left(1-\rho_{G}\right) \zeta^{G}\left(\ln \left|\frac{B_{t+1}}{P_{t}^{Y} Y_{t}}\right|-\ln \left|\frac{\bar{B}_{t+1}}{\bar{P}_{t}^{Y} \bar{Y}_{t}}\right|\right)+v_{t}^{G},
$$

where $0 \leq \rho_{G}<1$. As specified, the deviation of the ratio of nominal government consumption to nominal output from its deterministic steady state equilibrium value depends on an average of its past deviation and its desired deviation, which in turn depends on the contemporaneous deviation of the ratio of the net foreign asset position to nominal output from its target value. This fiscal expenditure rule supports a determinate rational expectations equilibrium only if the net foreign asset position does not change sign. If the net foreign asset position is positive then $\zeta^{G}>0$, while if it is negative then $\zeta^{G}<0$. Transitory departures from this fiscal expenditure rule are captured by serially uncorrelated fiscal expenditure shock $v_{t}^{G}$.

The tax rate applicable to the pooled labor income of households and the earnings of intermediate good firms satisfies a fiscal revenue rule exhibiting partial adjustment dynamics of the form

$$
\ln \tau_{t}-\ln \bar{\tau}_{t}=\rho_{\tau}\left(\ln \tau_{t-1}-\ln \bar{\tau}_{t-1}\right)+\left(1-\rho_{\tau}\right) \zeta^{\tau}\left(\ln \left|\frac{B_{t+1}^{G}}{P_{t}^{Y} Y_{t}}\right|-\ln \left|\frac{\bar{B}_{t+1}^{G}}{\bar{P}_{t}^{Y} \bar{Y}_{t}}\right|\right)+v_{t}^{\tau}
$$

where $0 \leq \rho_{\tau}<1$. As specified, the deviation of the tax rate from its deterministic steady state equilibrium value depends on its past deviation and its desired deviation, which in turn depends on the contemporaneous deviation of the ratio of the net government asset position to nominal output from its target value. This fiscal revenue rule supports a determinate rational expectations equilibrium only if the net government asset position does not change sign. If the net government asset position is positive then $\zeta^{\tau}<0$, while if it is negative then $\zeta^{\tau}>0$. Transitory departures from this fiscal revenue rule are captured by serially uncorrelated fiscal revenue shock $v_{t}^{\tau}$.

The fiscal authority enters period $t$ holding previously purchased domestic currency denominated bonds $B_{t}^{G, h}$ which yield interest at risk free rate $i_{t-1}$, and foreign currency denominated bonds $B_{t}^{G, f}$ which yield interest at risk free rate $i_{t-1}^{f}$. Its foreign exchange transactions are subject to consolidated fee $f_{t}$. The fiscal authority also levies taxes on the pooled labor income of households and the earnings of intermediate good firms. These sources of public wealth are summed in government dynamic budget constraint: 


$$
\begin{aligned}
B_{t+1}^{G, h}+ & \mathcal{E}_{t} B_{t+1}^{G, f}=\left(1+i_{t-1}\right) B_{t}^{G, h}+\mathcal{E}_{t}\left(1-f_{t}\right)\left(1+i_{t-1}^{f}\right) B_{t}^{G, f} \\
& +\tau_{t} \int_{i=0}^{1} \int_{h=0}^{1} W_{h, t}^{l} L_{h, t}^{l} d h d i+\tau_{t} \int_{j=0}^{1}\left(P_{j, t}^{Y} Y_{j, t}-W_{t} L_{j, t}\right) d j-P_{t}^{G} G_{t} .
\end{aligned}
$$

According to this dynamic budget constraint, at the end of period $t$, the fiscal authority purchases domestic bonds $B_{t+1}^{G, h}$, and foreign bonds $B_{t+1}^{G, f}$ at price $\mathcal{E}_{t}$. It also purchases final government consumption good $G_{t}$ at price $P_{t}^{G}$.

\section{Market Clearing Conditions}

A rational expectations equilibrium in this DSGE model of a small open economy consists of state contingent intertemporal allocations for domestic and foreign households and firms which solve their constrained optimization problems given prices and policy, together with state contingent intertemporal allocations for domestic and foreign governments which satisfy their policy rules and constraints given prices, with supporting prices such that all markets clear. Since the domestic economy is small relative to the foreign economy, in $\underset{M_{t}^{n, f}}{\text { equilibrium }} M_{M^{e, f}} P_{t}^{Y, f} \approx P_{t}^{C, f} \approx P_{t}^{I, f} \approx P_{t}^{G, f} \approx P_{t}^{X, f} \approx P_{t}^{X^{n}, f} \approx P_{t}^{X^{e}, f}$ and $\frac{X_{t}^{f}}{Y_{t}^{f}} \approx \frac{X_{t}^{n, f}}{Y_{t}^{f}} \approx \frac{X_{t}^{e, f}}{Y_{t}^{f}} \approx \frac{M_{t}^{f}}{Y_{t}^{f}} \approx$ $\frac{M_{t}^{n, f}}{Y_{t}^{f}} \approx \frac{M_{t}^{e, f}}{Y_{t}^{f}} \approx \frac{B_{t+1}^{f}}{P_{t}^{f} Y_{t}^{f}} \approx 0$.

Clearing of the final output good market requires that nonentrepôt exports $X_{t}^{n}$ equal production of the domestic final output good less the cumulative demands of domestic households, firms, and the government,

$$
X_{t}^{n}=Y_{t}-C_{h, t}-I_{h, t}-G_{h, t}
$$

where $X_{t}^{n}=M_{t}^{n, f}$ and $X_{t}^{e}=M_{t}^{e, f}$. Clearing of the final nonentrepôt import good market requires that nonentrepôt imports $M_{t}^{n}$ satisfy the cumulative demands of domestic households, firms, and the government for the foreign final output good,

$$
M_{t}^{n}=C_{f, t}+I_{f, t}+G_{f, t}
$$

where $M_{t}^{n}=X_{t}^{n, f}$ and $M_{t}^{e}=X_{t}^{e, f}$. In equilibrium, combination of these final output and nonentrepôt import good market clearing conditions yields aggregate resource constraint:

$$
P_{t}^{Y} Y_{t}=P_{t}^{C} C_{t}+P_{t}^{I} I_{t}+P_{t}^{G} G_{t}+P_{t}^{X^{n}} X_{t}^{n}-P_{t}^{M^{n}} M_{t}^{n}
$$

The trade balance equals export revenues $P_{t}^{X} X_{t}=P_{t}^{X^{n}} X_{t}^{n}+P_{t}^{X^{e}} X_{t}^{e}$ less import expenditures $P_{t}^{M} M_{t}=P_{t}^{M^{n}} M_{t}^{n}+P_{t}^{M^{e}} M_{t}^{e}$. 
Let $B_{t+1}$ denote the net foreign asset position of the economy, which in equilibrium equals the sum of the domestic currency values of private sector bond holdings $B_{t+1}^{P}=B_{t+1}^{P, h}+\mathcal{E}_{t} B_{t+1}^{P, f}$ and public sector bond holdings $B_{t+1}^{G}=B_{t+1}^{G, h}+\mathcal{E}_{t} B_{t+1}^{G, f}$ :

$$
B_{t+1}=B_{t+1}^{P}+B_{t+1}^{G} .
$$

The imposition of equilibrium conditions on household dynamic budget constraint (5) reveals that the net increase in private sector asset holdings equals private saving less investment:

$$
B_{t+1}^{P}=\left(1+i_{t-1}\right) B_{t}^{P}+\left(1-\tau_{t}\right) P_{t}^{Y} Y_{t}+P_{t}^{X^{e}} X_{t}^{e}-P_{t}^{M^{e}} M_{t}^{e}-P_{t}^{C} C_{t}-P_{t}^{I} I_{t} .
$$

The imposition of equilibrium conditions on government dynamic budget constraint (67) reveals that the net increase in public sector asset holdings equals public saving:

$$
B_{t+1}^{G}-B_{t}^{G}=i_{t-1} B_{t}^{G}+\tau_{t} P_{t}^{Y} Y_{t}-P_{t}^{G} G_{t} .
$$

Combination of these household and government dynamic budget constraints with aggregate resource constraint (70) reveals that the net increase in foreign asset holdings equals the sum of net international investment income and the trade balance, or equivalently saving less investment:

$$
B_{t+1}-B_{t}=i_{t-1} B_{t}+P_{t}^{X} X_{t}-P_{t}^{M} M_{t}
$$

In equilibrium, the current account balance is determined by both intratemporal and intertemporal optimization.

\section{The Empirical Framework}

Estimation is based on an approximate linear unobserved components representation of this DSGE model of a small open economy under the restriction that all households supply differentiated intermediate skilled labor services, represented by $\varphi^{L}=0$. Inference is based on the approximate multivariate linear rational expectations representation of this DSGE model while relaxing this restriction for the domestic economy.

In what follows, $\mathrm{E}_{t} x_{t+s}$ denotes the rational expectation of variable $x_{t+s}$, conditional on information available at time $t$. Also, $\hat{x}_{t}$ denotes the cyclical component of variable $x_{t}$, while $\bar{x}_{t}$ denotes the trend component of variable $x_{t}$. Cyclical components are modeled by linearizing equilibrium conditions around a stationary deterministic steady state equilibrium which abstracts from long run balanced growth, while trend components are modeled as random walks while ensuring the existence of a well defined balanced growth path along 
which great ratios and trend growth rates are time independent but state dependent. Cyclical and trend components are additively separable, that is $x_{t}=\hat{x}_{t}+\bar{x}_{t}$.

\section{Cyclical Components}

The cyclical component of output price inflation depends on a linear combination of its past and expected future cyclical components driven by the contemporaneous cyclical components of real marginal cost and the tax rate according to output price Phillips curve

$$
\hat{\pi}_{t}^{Y}=\frac{\gamma^{Y}}{1+\gamma^{Y} \beta} \hat{\pi}_{t-1}^{Y}+\frac{\beta}{1+\gamma^{Y} \beta} \mathrm{E}_{t} \hat{\pi}_{t+1}^{Y}+\frac{\left(1-\omega^{Y}\right)\left(1-\omega^{Y} \beta\right)}{\omega^{Y}\left(1+\gamma^{Y} \beta\right)}\left[\ln \hat{\Phi}_{t}+\frac{\tau}{1-\tau} \ln \hat{\tau}_{t}-\frac{1}{\theta^{Y}-1} \ln \hat{\theta}_{t}^{Y}\right],
$$

where $\Phi=(1-\tau) \frac{\theta^{Y}-1}{\theta^{Y}}$. The persistence of the cyclical component of output price inflation is increasing in indexation parameter $\gamma^{Y}$, while the sensitivity of the cyclical component of output price inflation to changes in the cyclical components of real marginal cost and the tax rate is decreasing in nominal rigidity parameter $\omega^{Y}$ and indexation parameter $\gamma^{Y}$. This output price Phillips curve is subject to output price markup shocks.

The cyclical component of output depends on the contemporaneous cyclical components of utilized capital and effective labor according to approximate linear net production function

$$
\ln \hat{Y}_{t}=\left(1-\frac{\theta^{Y}}{\theta^{Y}-1} \frac{W L}{P Y}\right) \ln \left(\hat{u}_{t} \hat{K}_{t}\right)+\frac{\theta^{Y}}{\theta^{Y}-1} \frac{W L}{P Y} \ln \left(\hat{A}_{t} \hat{L}_{t}\right)
$$

where $\frac{K}{Y}=\frac{\beta(1-\tau)}{1-\beta(1-\delta)}\left(\frac{\theta^{Y}-1}{\theta^{Y}}-\frac{W L}{P Y}\right)$. This approximate linear net production function is subject to labor productivity shocks.

The cyclical component of the rate of capital utilization depends on the contemporaneous cyclical component of the ratio of capital to effective labor according to approximate linear implicit capital utilization function:

$$
\ln \hat{u}_{t}=-\frac{\theta^{Y}}{\theta^{Y}-1} \frac{W L}{P Y}\left(\kappa \vartheta+\frac{\theta^{Y}}{\theta^{Y}-1} \frac{W L}{P Y}\right)^{-1} \ln \frac{\hat{K}_{t}}{\hat{A}_{t} \hat{L}_{t}} .
$$

The sensitivity of the cyclical component of the rate of capital utilization to changes in the cyclical component of the ratio of capital to effective labor is decreasing in capital utilization cost parameter $\kappa$ and elasticity of substitution parameter $\vartheta$. This approximate linear implicit capital utilization function is subject to labor productivity shocks.

The cyclical component of consumption, investment or government consumption price inflation depends on a linear combination of its past and expected future cyclical components 
driven by the contemporaneous cyclical components of real marginal cost and the tax rate according to Phillips curves:

$$
\begin{aligned}
\hat{\pi}_{t}^{Z}= & \frac{\gamma^{Y}}{1+\gamma^{Y} \beta} \hat{\pi}_{t-1}^{Z}+\frac{\beta}{1+\gamma^{Y} \beta} \mathrm{E}_{t} \hat{\pi}_{t+1}^{Z}+\frac{\left(1-\omega^{Y}\right)\left(1-\omega^{Y} \beta\right)}{\omega^{Y}\left(1+\gamma^{Y} \beta\right)}\left[\ln \hat{\Phi}_{t}+\frac{\tau}{1-\tau} \ln \hat{\tau}_{t}-\frac{1}{\theta^{Y}-1} \ln \hat{\theta}_{t}^{Y}\right] \\
& -\frac{\gamma^{Y}\left(1-\phi^{Z}\right)}{1+\gamma^{Y} \beta} \Delta \ln \frac{\hat{\mathcal{T}}_{t-1}^{n}}{\hat{v}_{t-1}^{M}}+\left(1-\phi^{Z}\right) \Delta \ln \frac{\hat{\mathcal{T}}_{t}^{n}}{\hat{v}_{t}^{M}}-\frac{\beta\left(1-\phi^{Z}\right)}{1+\gamma^{Y} \beta} \mathrm{E}_{t} \Delta \ln \frac{\hat{\mathcal{T}}_{t+1}^{n}}{\hat{v}_{t+1}^{M}}
\end{aligned}
$$

Reflecting the entry of the price of nonentrepôt imports into the aggregate consumption, investment or government consumption price index, the cyclical component of consumption, investment or government consumption price inflation also depends on past, contemporaneous, and expected future changes in the cyclical component of the terms of trade. These Phillips curves are subject to output price markup and import productivity shocks.

The cyclical component of consumption depends on an average of its past and expected future cyclical components driven by the contemporaneous cyclical component of the consumption based real interest rate according to approximate linear consumption Euler equation:

$$
\ln \hat{C}_{t}=\frac{\alpha^{C}}{1+\alpha^{C}} \ln \hat{C}_{t-1}+\frac{1}{1+\alpha^{C}} \mathrm{E}_{t} \ln \hat{C}_{t+1}-\sigma \frac{1-\alpha^{C}}{1+\alpha^{C}}\left[\hat{r}_{t}^{C}+\mathrm{E}_{t} \ln \frac{\hat{v}_{t+1}^{C}}{\hat{v}_{t}^{C}}\right]
$$

The persistence of the cyclical component of consumption is increasing in habit persistence parameter $\alpha^{C}$, while the sensitivity of the cyclical component of consumption to changes in the cyclical component of the consumption based real interest rate is increasing in intertemporal elasticity of substitution parameter $\sigma$ and decreasing in habit persistence parameter $\alpha^{C}$. This approximate linear consumption Euler equation is subject to preference shocks.

The cyclical component of investment depends on an average of its past and expected future cyclical components driven by the contemporaneous cyclical component of the relative shadow price of capital according to approximate linear investment demand function:

$$
\ln \hat{I}_{t}=\frac{1}{1+\beta} \ln \hat{I}_{t-1}+\frac{\beta}{1+\beta} \mathrm{E}_{t} \ln \hat{I}_{t+1}+\frac{1}{\chi(1+\beta)} \ln \left(\hat{v}_{t}^{I} \frac{\hat{Q}_{t}}{\hat{P}_{t}^{I}}\right)
$$

The sensitivity of the cyclical component of investment to changes in the cyclical component of the relative shadow price of capital is decreasing in capital investment adjustment cost 
parameter $\chi$. This approximate linear investment demand function is subject to investment productivity shocks.

The cyclical component of the relative shadow price of capital depends on its expected future cyclical component, the contemporaneous cyclical component of the output based real interest rate, the expected future cyclical component of real marginal cost, and the expected future cyclical component of the marginal product of capital according to approximate linear investment Euler equation:

$$
\begin{aligned}
\ln \frac{\hat{Q}_{t}}{\hat{P}_{t}}= & \beta(1-\delta) \mathrm{E}_{t} \ln \frac{\hat{Q}_{t+1}}{\hat{P}_{t+1}} \\
& \quad-\hat{r}_{t}^{Y}+[1-\beta(1-\delta)] \mathrm{E}_{t} \ln \hat{\Phi}_{t+1}-\frac{1-\beta(1-\delta)}{\vartheta} \frac{\theta^{Y}}{\theta^{Y}-1} \frac{W L}{P Y} \mathrm{E}_{t} \ln \frac{\hat{u}_{t+1} \hat{K}_{t+1}}{\hat{A}_{t+1} \hat{L}_{t+1}} .
\end{aligned}
$$

The sensitivity of the cyclical component of the relative shadow price of capital to changes in the cyclical component of the ratio of utilized capital to effective labor is decreasing in elasticity of substitution parameter $\vartheta$. This approximate linear investment Euler equation is subject to labor productivity shocks.

The cyclical component of the capital stock depends on its past cyclical component and the contemporaneous cyclical component of investment according to approximate linear capital accumulation function

$$
\ln \hat{K}_{t+1}=(1-\delta) \ln \hat{K}_{t}+\delta \ln \left(\hat{v}_{t}^{I} \hat{I}_{t}\right)
$$

where $\frac{I}{K}=\delta$. This approximate linear capital accumulation function is subject to investment productivity shocks.

The cyclical component of the ratio of nominal government consumption to nominal output depends on its past cyclical component and the contemporaneous cyclical component of the ratio of the net foreign asset position to nominal output according to fiscal expenditure rule:

$$
\ln \frac{\hat{P}_{t}^{G} \hat{G}_{t}}{\hat{P}_{t}^{Y} \hat{Y}_{t}}=\rho_{G} \ln \frac{\hat{P}_{t-1}^{G} \hat{G}_{t-1}}{\hat{P}_{t-1}^{Y} \hat{Y}_{t-1}}+\left(1-\rho_{G}\right) \zeta^{G} \ln \left|\frac{\hat{B}_{t+1}}{\hat{P}_{t}^{Y} \hat{Y}_{t}}\right|+\hat{v}_{t}^{G} .
$$

This fiscal expenditure rule ensures convergence of the level of the ratio of the net foreign asset position to nominal output to its target value in deterministic steady state equilibrium, and is subject to fiscal expenditure shocks. 
The cyclical component of the tax rate depends on its past cyclical component and the contemporaneous cyclical component of the ratio of the net government asset position to nominal output according to fiscal revenue rule:

$$
\ln \hat{\tau}_{t}=\rho_{\tau} \ln \hat{\tau}_{t-1}+\left(1-\rho_{\tau}\right) \zeta^{\tau} \ln \left|\frac{\hat{B}_{t+1}^{G}}{\hat{P}_{t}^{Y} \hat{Y}_{t}}\right|+\hat{v}_{t}^{\tau}
$$

This fiscal revenue rule ensures convergence of the level of the ratio of the net government asset position to nominal output to its target value in deterministic steady state equilibrium, and is subject to fiscal revenue shocks.

The cyclical component of export price inflation depends on an average of the contemporaneous cyclical components of nonentrepôt and entrepôt export price inflation:

$$
\hat{\pi}_{t}^{X}=\phi^{X} \hat{\pi}_{t}^{X^{n}}+\left(1-\phi^{X}\right) \hat{\pi}_{t}^{X^{e}} .
$$

The cyclical component of export revenues satisfies $\frac{X}{Y} \ln \left(\hat{P}_{t}^{X} \hat{X}_{t}\right)=\frac{X^{n}}{Y} \ln \left(\hat{P}_{t}^{X^{n}} \hat{X}_{t}^{n}\right)+$ $\frac{X^{e}}{Y} \ln \left(\hat{P}_{t}^{X^{e}} \hat{X}_{t}^{e}\right)$, where $\frac{X}{Y}=\frac{X^{n}}{Y}+\frac{X^{e}}{Y}$.

The cyclical component of entrepôt export price inflation depends on a linear combination of its past and expected future cyclical components driven by the contemporaneous cyclical component of the deviation of the domestic currency price of entrepôt imports from the price of entrepôt exports according to export price Phillips curve:

$$
\hat{\pi}_{t}^{X^{e}}=\frac{\gamma^{X}}{1+\gamma^{X} \beta} \hat{\pi}_{t-1}^{X^{e}}+\frac{\beta}{1+\gamma^{X} \beta} \mathrm{E}_{t} \hat{\pi}_{t+1}^{X^{e}}+\frac{\left(1-\omega^{X}\right)\left(1-\omega^{X} \beta\right)}{\omega^{X}\left(1+\gamma^{X} \beta\right)}\left[\ln \frac{\hat{P}_{t}^{M^{e}}}{\hat{P}_{t}^{X^{e}}}-\frac{1}{\theta^{X}-1} \ln \hat{\theta}_{t}^{X}\right] .
$$

The persistence of the cyclical component of entrepôt export price inflation is increasing in indexation parameter $\gamma^{X}$, while the sensitivity of the cyclical component of entrepôt export price inflation to changes in the cyclical component of real marginal cost is decreasing in nominal rigidity parameter $\omega^{X}$ and indexation parameter $\gamma^{X}$. This export price Phillips curve is subject to export price markup shocks.

The cyclical component of exports depends on the contemporaneous cyclical components of foreign consumption, investment, government consumption, and the terms of trade according to approximate linear export demand function 


$$
\begin{gathered}
\frac{X}{Y} \frac{Y}{Y^{f}} \ln \hat{X}_{t}=\left(1-\phi^{C^{f}}\right) \frac{C^{f}}{Y^{f}} \ln \frac{\hat{C}_{t}^{f}}{\hat{v}_{t}^{M, f}}+\left(1-\phi^{I, f}\right) \frac{I}{Y} \ln \frac{\hat{I}_{t}^{f}}{\hat{v}_{t}^{M, f}}+\left(1-\phi^{G^{f}}\right) \frac{G}{Y} \ln \frac{\hat{G}_{t}^{f}}{\hat{v}_{t}^{M, f}} \\
-\psi^{f}\left[\phi^{C^{f}}\left(1-\phi^{C^{f}}\right) \frac{C^{f}}{Y^{f}}+\phi^{I, f}\left(1-\phi^{I, f}\right) \frac{I}{Y}+\phi^{G^{f}}\left(1-\phi^{G^{f}}\right) \frac{G}{Y}\right] \ln \frac{\hat{\mathcal{T}}_{t}^{f}}{\hat{v}_{t}^{M, f}},
\end{gathered}
$$

where $\frac{Y}{Y^{f}} \frac{X}{Y}=\left(1-\phi^{C^{f}}\right) \frac{C^{f}}{Y^{f}}+\left(1-\phi^{I, f}\right) \frac{I^{f}}{Y \hat{P}^{X^{e}}}\left(1-\phi^{G, f}\right) \frac{G^{f}}{X^{X^{f}}}$. The cyclical component of entrepôt exports satisfies $\ln \hat{X}_{t}^{e}=\ln \hat{X}_{t}-\psi^{X} \ln \frac{Y_{t}^{\hat{t}_{t}}}{\hat{P}^{X^{X}}}$, where $\frac{X^{X^{c^{f}}}}{Y}=\left(1-\phi^{X}\right) \frac{X}{Y}$. The sensitivity of the cyclical component of exports to changés in the cyclical component of the foreign terms of trade is increasing in elasticity of substitution parameter $\psi^{f}$. This approximate linear export demand function is subject to foreign import productivity shocks.

The cyclical component of import price inflation depends on an average of the contemporaneous cyclical components of nonentrepôt and entrepôt import price inflation:

$$
\hat{\pi}_{t}^{M}=\phi^{M} \hat{\pi}_{t}^{M^{n}}+\left(1-\phi^{M}\right) \hat{\pi}_{t}^{M^{e}} .
$$

The cyclical component of import expenditures satisfies $\frac{M}{Y} \ln \left(\hat{P}_{t}^{M} \hat{M}_{t}\right)=\frac{M^{n}}{Y} \ln \left(\hat{P}_{t}^{M^{n}} \hat{M}_{t}^{n}\right)+$ $\frac{M^{e}}{Y} \ln \left(\hat{P}_{t}^{M^{e}} \hat{M}_{t}^{e}\right)$, where $\frac{M}{Y}=\frac{M^{n}}{Y}+\frac{M^{e}}{Y}$.

The cyclical component of nonentrepôt or entrepôt import price inflation depends on a linear combination of its past and expected future cyclical components driven by the contemporaneous cyclical component of the deviation of the domestic currency price of foreign output from the price of nonentrepôt or entrepôt imports according to import price Phillips curves:

$$
\hat{\pi}_{t}^{M^{2}}=\frac{\gamma^{M}}{1+\gamma^{M} \beta} \hat{\pi}_{t-1}^{M^{2}}+\frac{\beta}{1+\gamma^{M} \beta} \mathrm{E}_{t} \hat{\pi}_{t+1}^{M^{2}}+\frac{\left(1-\omega^{M}\right)\left(1-\omega^{M} \beta\right)}{\omega^{M}\left(1+\gamma^{M} \beta\right)}\left[\ln \frac{\hat{\mathcal{E}}_{t} \hat{P}_{t}^{Y, f}}{\hat{P}_{t}^{M^{2}}}-\frac{1}{\theta^{M}-1} \ln \hat{\theta}_{t}^{M}\right] .
$$

The persistence of the cyclical component of nonentrepôt or entrepôt import price inflation is increasing in indexation parameter $\gamma^{M}$, while the sensitivity of the cyclical component of nonentrepôt or entrepôt import price inflation to changes in the cyclical component of real marginal cost is decreasing in nominal rigidity parameter $\omega^{M}$ and indexation parameter $\gamma^{M}$. These import price Phillips curves are subject to import price markup shocks.

The cyclical component of nonentrepôt imports depends on the contemporaneous cyclical components of consumption, investment, government consumption, and the terms of trade according to approximate linear import demand function 


$$
\begin{gathered}
\frac{M^{n}}{Y} \ln \hat{M}_{t}^{n}=\left(1-\phi^{C}\right) \frac{C}{Y} \ln \frac{\hat{C}_{t}}{\hat{v}_{t}^{M}}+\left(1-\phi^{I}\right) \frac{I}{Y} \ln \frac{\hat{I}_{t}}{\hat{v}_{t}^{M}}+\left(1-\phi^{G}\right) \frac{G}{Y} \ln \frac{\hat{G}_{t}}{\hat{v}_{t}^{M}} \\
-\psi\left[\phi^{C}\left(1-\phi^{C}\right) \frac{C}{Y}+\phi^{I}\left(1-\phi^{I}\right) \frac{I}{Y}+\phi^{G}\left(1-\phi^{G}\right) \frac{G}{Y}\right] \ln \frac{\hat{\mathcal{T}}_{t}^{n}}{\hat{v}_{t}^{M}},
\end{gathered}
$$

where $\frac{M^{n}}{Y}=\left(1-\phi^{C}\right) \frac{C}{X}+\left(1-\phi^{I}\right) \frac{I}{\hat{P}^{M} e^{e}}+\left(1-\phi^{G}\right) \frac{G}{Y_{M}}$. The cyclical component of entrepôt imports satisfies $\ln \hat{M}_{t}^{e}=\ln M_{t}-\psi^{M} \ln \frac{\hat{P}_{t}^{M^{e}}}{\hat{P}^{M}}$, where $\frac{Y_{M}^{e}}{Y}=\left(1-\phi^{M}\right) \frac{M}{Y}$. The sensitivity of the cyclical component of nonentrepôt imports to changes in the cyclical component of the terms of trade is increasing in elasticity of substitution parameter $\psi$. This approximate linear nonentrepôt import demand function is subject to import productivity shocks.

The cyclical component of the effective wage depends on an average of the contemporaneous cyclical components of the unskilled and skilled effective wages:

$$
\ln \frac{\hat{W}_{t}}{\hat{A}_{t}}=\varphi^{L} \ln \frac{\hat{W}_{t}^{u}}{\hat{A}_{t}^{u}}+\left(1-\varphi^{L}\right) \ln \frac{\hat{W}_{t}^{s}}{\hat{A}_{t}^{s}} .
$$

The cyclical components of unskilled and skilled employment satisfy $\ln \left(\hat{A}_{t}^{l} \hat{L}_{t}^{l}\right)=\ln \left(\hat{A}_{t} \hat{L}_{t}\right)-$ $\vartheta \ln \frac{\tilde{W}_{t}^{l} / \hat{A}_{t}^{l}}{\hat{W}_{t} / \hat{A}_{t}}$.

The cyclical component of the skilled or unskilled wage depends on an average of its past and expected future cyclical components driven by the contemporaneous cyclical component of the deviation of the marginal rate of substitution between leisure and consumption from the after tax real wage according to wage Phillips curves:

$$
\begin{aligned}
\ln \frac{\hat{W}_{t}^{l}}{\hat{W}_{t}^{I_{l}}}= & \frac{1}{1+\beta} \ln \frac{\hat{W}_{t-1}^{l}}{\hat{W}_{t-1}^{I_{l}}}+\frac{\beta}{1+\beta} \mathrm{E}_{t} \ln \frac{\hat{W}_{t+1}^{l}}{\hat{W}_{t+1}^{I_{l}}} \\
& +\frac{\left(1-\omega^{L_{l}}\right)\left(1-\omega^{L_{l}} \beta\right)}{\omega^{L_{l}}(1+\beta)}\left[\frac{1}{\eta} \frac{\ln \hat{L}_{t}^{l}-\alpha^{L} \ln \hat{L}_{t-1}^{l}}{1-\alpha^{L}}+\frac{1}{\sigma} \frac{\ln \hat{C}_{t}-\alpha^{C} \ln \hat{C}_{t-1}}{1-\alpha^{C}}+\frac{\tau}{1-\tau} \ln \hat{\tau}_{t}-\ln \frac{\hat{W}_{t}^{l}}{\hat{P}_{t}^{C}}-\frac{1}{\theta^{L}-1} \ln \hat{\theta}_{t}^{L}\right] .
\end{aligned}
$$

Reflecting the existence of wage indexation, the cyclical component of the skilled or unskilled wage also depends on past, contemporaneous, and expected future cyclical components of the indexed wage. The sensitivity of the cyclical component of the skilled or unskilled wage to changes in the cyclical component of the deviation of the marginal rate of substitution between leisure and consumption from the after tax real wage is decreasing in nominal rigidity parameter $\omega^{L_{l}}$, and to changes in the cyclical component of adjusted employment is decreasing in elasticity of substitution parameter $\eta$. These wage Phillips curves are subject to wage markup shocks. 
The cyclical component of skilled or unskilled indexed wage inflation depends on past aggregate wage inflation, consumption price inflation and average labor productivity growth according to indexation rule:

$$
\ln \hat{W}_{t}^{I_{l}}=\gamma^{L_{l}, W} \ln \frac{\hat{W}_{t-1}}{\hat{W}_{t-2}}+\gamma^{L_{l}, P} \ln \frac{\hat{P}_{t-1}^{C}}{\hat{P}_{t-2}^{C}}+\gamma^{L_{l}, y} \ln \frac{\hat{y}_{t-1}}{\hat{y}_{t-2}}+\ln \hat{W}_{t-1}^{I_{l}} .
$$

The sensitivity of the cyclical component of skilled or unskilled indexed wage inflation to changes in the cyclical component of wage inflation is increasing in indexation parameter $\gamma^{L_{1}, W}$, to changes in the cyclical component of consumption price inflation is increasing in indexation parameter $\gamma^{L_{l}, P}$, and to changes in the cyclical component of labor productivity growth is increasing in indexation parameter $\gamma^{L_{1}, y}$. The cyclical component of average labor productivity satisfies $\ln \hat{y}_{t}=\ln \hat{Y}_{t}-\ln \hat{L}_{t}$.

The cyclical component of real marginal cost depends on the contemporaneous cyclical component of the deviation of the after tax real wage from the marginal product of labor according to approximate linear implicit labor demand function:

$$
\ln \hat{\Phi}_{t}=\ln \frac{\hat{W}_{t}}{\hat{P}_{t}^{Y} \hat{A}_{t}}-\frac{\tau}{1-\tau} \ln \hat{\tau}_{t}-\frac{1}{\vartheta}\left(1-\frac{\theta^{Y}}{\theta^{Y}-1} \frac{W L}{P Y}\right) \ln \frac{\hat{u}_{t} \hat{K}_{t}}{\hat{A}_{t} \hat{L}_{t}} .
$$

The sensitivity of the cyclical component of real marginal cost to changes in the cyclical component of the ratio of utilized capital to effective labor is decreasing in elasticity of substitution parameter $\vartheta$. This approximate linear implicit labor demand function is subject to labor productivity shocks.

The cyclical component of the nominal interest rate depends on its past cyclical component and the contemporaneous cyclical components of consumption price inflation, output, the foreign nominal interest rate, and the nominal exchange rate according to monetary policy rule:

$$
\hat{i}_{t}=\rho_{i} \hat{i}_{t-1}+\left(1-\rho_{i}\right)\left(\xi^{\pi} \hat{\pi}_{t}^{C}+\xi^{Y} \ln \hat{Y}_{t}+\xi^{i} \hat{i}_{t}^{f}+\xi^{\mathcal{E}} \ln \hat{\mathcal{E}}_{t}\right)+v_{t}^{i} .
$$

This monetary policy rule nests those followed by the domestic and foreign monetary authorities under parameter restrictions, and is subject to monetary policy shocks. The cyclical component of the output based real interest rate satisfies $\hat{r}_{t}^{Y}=\hat{i}_{t}-\mathrm{E}_{t} \hat{\pi}_{t+1}^{Y}$, while the cyclical component of the consumption based real interest rate satisfies $\hat{r}_{t}^{C}=\hat{i}_{t}-\mathrm{E}_{t} \hat{\pi}_{t+1}^{C}$.

The cyclical component of the nominal exchange rate depends on its expected future cyclical component and the contemporaneous cyclical component of the nominal interest rate differential according to approximate linear uncovered interest parity condition: 


$$
\ln \hat{\mathcal{E}}_{t}=\mathrm{E}_{t} \ln \hat{\mathcal{E}}_{t+1}-\left(\hat{i}_{t}-\hat{i}_{t}^{f}\right)-\mathrm{E}_{t} \hat{f}_{t+1} \text {. }
$$

This approximate linear uncovered interest parity condition is subject to foreign exchange transaction cost shocks. The cyclical component of the real exchange rate satisfies $\ln \hat{\mathcal{Q}}_{t}=\ln \hat{\mathcal{E}}_{t}+\ln \hat{P}_{t}^{Y, f}-\ln \hat{P}_{t}^{Y}$, while the cyclical component of the terms of trade satisfies $\ln \hat{\mathcal{T}}_{t}^{z}=\ln \hat{P}_{t}^{M^{z}}-\ln \hat{P}_{t}^{X^{z}}$, where $\ln \hat{P}_{t}^{X^{n}}=\ln \hat{P}_{t}^{Y}$.

The cyclical component of nominal output depends on the contemporaneous cyclical components of nominal consumption, investment, government consumption, nonentrepôt exports, and nonentrepôt imports according to approximate linear aggregate resource constraint:

$$
\ln \left(\hat{P}_{t}^{Y} \hat{Y}_{t}\right)=\frac{C}{Y} \ln \left(\hat{P}_{t}^{C} \hat{C}_{t}\right)+\frac{I}{Y} \ln \left(\hat{P}_{t}^{I} \hat{I}_{t}\right)+\frac{G}{Y} \ln \left(\hat{P}_{t}^{G} \hat{G}_{t}\right)+\frac{X^{n}}{Y} \ln \left(\hat{P}_{t}^{X^{n}} \hat{X}_{t}^{n}\right)-\frac{M^{n}}{Y} \ln \left(\hat{P}_{t}^{M^{n}} \hat{M}_{t}^{n}\right) .
$$

In equilibrium, the cyclical component of output is determined by the cumulative demands of domestic and foreign households, firms, and governments.

The cyclical component of the net government asset position depends on its past cyclical component, the past cyclical component of the nominal interest rate, the contemporaneous cyclical component of tax revenues, and the contemporaneous cyclical component of nominal government consumption according to approximate linear government dynamic budget constraint

$$
\ln \left|\hat{B}_{t+1}^{G}\right|=\frac{1}{\beta}\left[\ln \left|\hat{B}_{t}^{G}\right|+\hat{i}_{t-1}\right]+\left(\frac{B^{G}}{P Y}\right)^{-1}\left[\tau \ln \left(\hat{\tau}_{t} \hat{P}_{t}^{Y} \hat{Y}_{t}\right)-\frac{G}{Y} \ln \left(\hat{P}_{t}^{G} \hat{G}_{t}\right)\right],
$$

where $\frac{B^{G}}{P Y}=-\frac{\beta}{1-\beta}\left(\tau-\frac{G}{Y}\right)$. This approximate linear government dynamic budget constraint supports determinacy only if the level of the net government asset position does not change sign.

The cyclical component of the net foreign asset position depends on its past cyclical component, the past cyclical component of the nominal interest rate, the contemporaneous cyclical component of export revenues, and the contemporaneous cyclical component of import expenditures according to approximate linear national dynamic budget constraint

$$
\ln \left|\hat{B}_{t+1}\right|=\frac{1}{\beta}\left[\ln \left|\hat{B}_{t}\right|+\hat{i}_{t-1}\right]+\left(\frac{B}{P Y}\right)^{-1}\left[\frac{X}{Y} \ln \left(\hat{P}_{t}^{X} \hat{X}_{t}\right)-\frac{M}{Y} \ln \left(\hat{P}_{t}^{M} \hat{M}_{t}\right)\right],
$$


where $\frac{B}{P Y}=-\frac{\beta}{1-\beta}\left(\frac{X}{Y}-\frac{M}{Y}\right)$. This approximate linear national dynamic budget constraint supports determinacy only if the level of the net foreign asset position does not change sign.

Variation in cyclical components is driven by twelve exogenous stochastic processes, one of which is common to the domestic and foreign economies. The cyclical components of the preference, labor productivity, investment productivity, import productivity, output price markup, export price markup, import price markup, and wage markup shocks follow stationary first order autoregressive processes:

$$
\begin{gathered}
\ln \hat{v}_{t}^{C}=\rho_{v^{C}} \ln \hat{v}_{t-1}^{C}+\varepsilon_{t}^{v^{C}}, \varepsilon_{t}^{v^{C}} \sim \text { iid } \mathcal{N}\left(0, \sigma_{v^{C}}^{2}\right), \\
\ln \hat{A}_{t}=\rho_{A} \ln \hat{A}_{t-1}+\varepsilon_{t}^{A}, \varepsilon_{t}^{A} \sim \operatorname{iid} \mathcal{N}\left(0, \sigma_{A}^{2}\right), \\
\ln \hat{v}_{t}^{I}=\rho_{v^{I}} \ln \hat{v}_{t-1}^{I}+\varepsilon_{t}^{v^{I}}, \varepsilon_{t}^{v^{I}} \sim \operatorname{iid} \mathcal{N}\left(0, \sigma_{v^{I}}^{2}\right), \\
\ln \hat{v}_{t}^{M}=\rho_{v^{M}} \ln \hat{v}_{t-1}^{M}+\varepsilon_{t}^{v^{M}}, \varepsilon_{t}^{v^{M}} \sim \operatorname{iid} \mathcal{N}\left(0, \sigma_{v^{M}}^{2}\right), \\
\ln \hat{\theta}_{t}^{Y}=\rho_{\theta^{Y}} \ln \hat{\theta}_{t-1}^{Y}+\varepsilon_{t}^{\theta^{Y}}, \varepsilon_{t}^{\theta^{Y}} \sim \operatorname{iid} \mathcal{N}\left(0, \sigma_{\theta^{Y}}^{2}\right), \\
\ln \hat{\theta}_{t}^{X}=\rho_{\theta^{X}} \ln \hat{\theta}_{t-1}^{X}+\varepsilon_{t}^{\theta^{X}}, \varepsilon_{t}^{\theta^{X}} \sim \operatorname{iid} \mathcal{N}\left(0, \sigma_{\theta^{X}}^{2}\right), \\
\ln \hat{\theta}_{t}^{M}=\rho_{\theta^{M}} \ln \hat{\theta}_{t-1}^{M}+\varepsilon_{t}^{\theta^{M}}, \varepsilon_{t}^{\theta^{M}} \sim \operatorname{iid} \mathcal{N}\left(0, \sigma_{\theta^{M}}^{2}\right), \\
\ln \hat{\theta}_{t}^{L}=\rho_{\theta^{L}} \ln \hat{\theta}_{t-1}^{L}+\varepsilon_{t}^{\theta^{L}}, \varepsilon_{t}^{\theta^{L}} \sim \operatorname{iid} \mathcal{N}\left(0, \sigma_{\theta^{L}}^{2}\right),
\end{gathered}
$$

The cyclical components of the unskilled and skilled labor productivity shocks satisfy $\ln \hat{A}_{t}^{l}=\ln \hat{A}_{t}$. The cyclical components of the monetary policy, fiscal expenditure, and fiscal revenue shocks follow white noise processes:

$$
\begin{gathered}
\hat{v}_{t}^{i}=\varepsilon_{t}^{v^{i}}, \varepsilon_{t}^{v^{i}} \sim \text { iid } \mathcal{N}\left(0, \sigma_{v^{i}}^{2}\right), \\
\hat{v}_{t}^{G}=\varepsilon_{t}^{v^{G}}, \varepsilon_{t}^{v^{G}} \sim \text { iid } \mathcal{N}\left(0, \sigma_{v^{G}}^{2}\right), \\
\hat{v}_{t}^{\tau}=\varepsilon_{t}^{v^{\tau}}, \varepsilon_{t}^{v^{\tau}} \sim \text { iid } \mathcal{N}\left(0, \sigma_{v^{\tau}}^{2}\right) .
\end{gathered}
$$

The cyclical component of the foreign exchange transaction cost shock follows a stationary first order autoregressive process: 


$$
\hat{f}_{t}=\rho_{f} \hat{f}_{t-1}+\varepsilon_{t}^{f}, \varepsilon_{t}^{f} \sim \operatorname{iid} \mathcal{N}\left(0, \sigma_{f}^{2}\right)
$$

The innovations driving these exogenous stochastic processes are assumed to be independent, which combined with our distributional assumptions implies multivariate normality. In deterministic steady state equilibrium, $v^{C}=v^{I}=v^{M}=1$ and $\sigma_{v^{C}}^{2}=\sigma_{A}^{2}=\sigma_{v^{I}}^{2}=\sigma_{v^{M}}^{2}=\sigma_{\theta^{Y}}^{2}=$ $\sigma_{\theta^{X}}^{2}=\sigma_{\theta^{M}}^{2}=\sigma_{\theta^{L}}^{2}=\sigma_{v^{i}}^{2}=\sigma_{v^{G}}^{2}=\sigma_{v^{\tau}}^{2}=\sigma_{f}^{2}=0$.

\section{Trend Components}

The trend components of the prices of output, consumption, investment, government consumption, exports, entrepôt exports, imports, and nonentrepôt imports follow random walks with time varying drift $\pi_{t}$ :

$$
\begin{gathered}
\ln \bar{P}_{t}^{Y}=\pi_{t}+\ln \bar{P}_{t-1}^{Y}+\varepsilon_{t}^{\bar{P}^{Y}}, \varepsilon_{t}^{\bar{P}^{Y}} \sim \text { iid } \mathcal{N}\left(0, \sigma_{\bar{P}^{Y}}^{2}\right), \\
\ln \bar{P}_{t}^{C}=\pi_{t}+\ln \bar{P}_{t-1}^{C}+\varepsilon_{t}^{\bar{P}^{C}}, \varepsilon_{t}^{\bar{P}^{C}} \sim \text { iid } \mathcal{N}\left(0, \sigma_{\bar{P}^{C}}^{2}\right), \\
\ln \bar{P}_{t}^{I}=\pi_{t}+\ln \bar{P}_{t-1}^{I}+\varepsilon_{t}^{\bar{P}^{I}}, \varepsilon_{t}^{\bar{P}^{I}} \sim \text { iid } \mathcal{N}\left(0, \sigma_{\bar{P}^{I}}^{2}\right), \\
\ln \bar{P}_{t}^{G}=\pi_{t}+\ln \bar{P}_{t-1}^{G}+\varepsilon_{t}^{\bar{P}^{G}}, \varepsilon_{t}^{\bar{P}^{G}} \sim \text { iid } \mathcal{N}\left(0, \sigma_{\bar{P}^{G}}^{2}\right), \\
\ln \bar{P}_{t}^{X}=\pi_{t}+\ln \bar{P}_{t-1}^{X}+\varepsilon_{t}^{\bar{P}^{X}}, \varepsilon_{t}^{\bar{P}^{X}} \sim \text { iid } \mathcal{N}\left(0, \sigma_{\bar{P}^{X}}^{2}\right), \\
\ln \bar{P}_{t}^{X^{e}}=\pi_{t}+\ln \bar{P}_{t-1}^{X^{e}}+\varepsilon_{t}^{\bar{P}^{x^{e}}}, \varepsilon_{t}^{\bar{P}^{x^{e}}} \sim \text { iid } \mathcal{N}\left(0, \sigma_{\bar{P}^{X^{e}}}^{2}\right), \\
\ln \bar{P}_{t}^{M}=\pi_{t}+\ln \bar{P}_{t-1}^{M}+\varepsilon_{t}^{\bar{P}^{M}}, \varepsilon_{t}^{\bar{P}^{M}} \sim \text { iid } \mathcal{N}\left(0, \sigma_{\bar{P}^{M}}^{2}\right), \\
\ln \bar{P}_{t}^{M^{n}}=\pi_{t}+\ln \bar{P}_{t-1}^{M^{n}}+\varepsilon_{t}^{\bar{P}^{M^{n}}}, \varepsilon_{t}^{\bar{P}^{M^{n}}} \sim \operatorname{iid} \mathcal{N}\left(0, \sigma_{\bar{P}^{M^{n}}}^{2}\right) .
\end{gathered}
$$

It follows that the trend components of the relative prices of consumption, investment, government consumption, exports, entrepôt exports, imports, and nonentrepôt imports follow random walks without drifts. This implies that along a balanced growth path, the levels of these relative prices are time independent but state dependent. The trend component of the price of nonentrepôt exports satisfies $\ln \bar{P}_{t}^{X^{n}}=\ln \bar{P}_{t}^{Y}$, while the trend component of the price of entrepôt imports satisfies $\ln \bar{P}_{t}^{M^{e}}=\ln \bar{P}_{t}^{Y}$. 
The trend components of output, consumption, investment, government consumption, exports, entrepôt exports, imports, and nonentrepôt imports follow random walks with time varying drift $g_{t}+n_{t}$ :

$$
\begin{gathered}
\ln \bar{Y}_{t}=g_{t}+n_{t}+\ln \bar{Y}_{t-1}+\varepsilon_{t}^{\bar{Y}}, \varepsilon_{t}^{\bar{Y}} \sim \text { iid } \mathcal{N}\left(0, \sigma_{\bar{Y}}^{2}\right), \\
\ln \bar{C}_{t}=g_{t}+n_{t}+\ln \bar{C}_{t-1}+\varepsilon_{t}^{\bar{C}}, \varepsilon_{t}^{\bar{C}} \sim \text { iid } \mathcal{N}\left(0, \sigma_{\bar{C}}^{2}\right), \\
\ln \bar{I}_{t}=g_{t}+n_{t}+\ln \bar{I}_{t-1}+\varepsilon_{t}^{\bar{I}}, \varepsilon_{t}^{\bar{I}} \sim \text { iid } \mathcal{N}\left(0, \sigma_{\bar{I}}^{2}\right), \\
\ln \bar{G}_{t}=g_{t}+n_{t}+\ln \bar{G}_{t-1}+\varepsilon_{t}^{\bar{G}}, \varepsilon_{t}^{\bar{G}} \sim \text { iid } \mathcal{N}\left(0, \sigma_{\bar{G}}^{2}\right), \\
\ln \bar{X}_{t}=g_{t}+n_{t}+\ln \bar{X}_{t-1}+\varepsilon_{t}^{\bar{X}}, \varepsilon_{t}^{\bar{X}} \sim \text { iid } \mathcal{N}\left(0, \sigma_{\bar{X}}^{2}\right), \\
\ln \bar{X}_{t}^{e}=g_{t}+n_{t}+\ln \bar{X}_{t-1}^{e}+\varepsilon_{t}^{\bar{X}^{e}}, \varepsilon_{t}^{\bar{X}^{e}} \sim \text { iid } \mathcal{N}\left(0, \sigma_{\bar{X}^{e}}^{2}\right), \\
\ln \bar{M}_{t}=g_{t}+n_{t}+\ln \bar{M}_{t-1}+\varepsilon_{t}^{\bar{M}}, \varepsilon_{t}^{\bar{M}} \sim \text { iid } \mathcal{N}\left(0, \sigma_{\bar{M}^{2}}^{2}\right), \\
\ln \bar{M}_{t}^{n}=g_{t}+n_{t}+\ln \bar{M}_{t-1}^{n}+\varepsilon_{t}^{\bar{M}^{n}}, \varepsilon_{t}^{\bar{M}^{n}} \sim \text { iid } \mathcal{N}\left(0, \sigma_{\bar{M}^{n}}^{2}\right)
\end{gathered}
$$

It follows that the trend components of the ratios of consumption, investment, government consumption, exports, entrepôt exports, imports, and nonentrepôt imports to output follow random walks without drifts. This implies that along a balanced growth path, the levels of these great ratios are time independent but state dependent. The trend component of

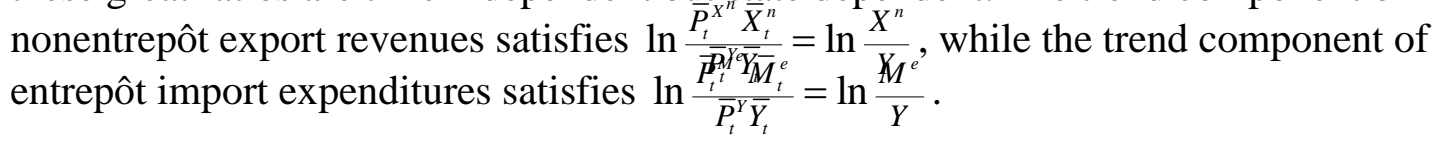

The trend component of the nominal wage follows a random walk with time varying drift $\pi_{t}+g_{t}$, while the trend component of employment follows a random walk with time varying drift $n_{t}$ :

$$
\begin{gathered}
\ln \bar{W}_{t}=\pi_{t}+g_{t}+\ln \bar{W}_{t-1}+\varepsilon_{t}^{\bar{W}}, \varepsilon_{t}^{\bar{W}} \sim \operatorname{iid} \mathcal{N}\left(0, \sigma_{\bar{W}}^{2}\right), \\
\ln \bar{L}_{t}=n_{t}+\ln \bar{L}_{t-1}+\varepsilon_{t}^{\bar{L}}, \varepsilon_{t}^{\bar{L}} \sim \operatorname{iid} \mathcal{N}\left(0, \sigma_{\bar{L}}^{2}\right)
\end{gathered}
$$

It follows that the trend component of the income share of labor follows a random walk without drift. This implies that along a balanced growth path, the level of the income share of labor is time independent but state dependent. The trend component of the indexed wage 
satisfies $\ln \bar{W}_{t}^{I}=\ln \bar{W}_{t}$, while the trend component of average labor productivity satisfies $\ln \bar{y}_{t}=\ln \bar{Y}_{t}-\ln \bar{L}_{t}$. The trend component of real marginal cost satisfies $\ln \bar{\Phi}_{t}=\ln \Phi$, while the trend component of the rate of capital utilization satisfies $\ln \bar{u}_{t}=0$. The trend component of the shadow price of capital satisfies $\ln \bar{Q}_{t}=\ln \bar{P}_{t}^{I}$, while the trend component of the capital stock satisfies $\ln \frac{\bar{K}_{t+1}}{\bar{Y}_{t}}=\ln \frac{K}{Y}$.

The trend components of the nominal interest rate, tax rate, and nominal exchange rate follow random walks without drifts:

$$
\begin{gathered}
\bar{i}_{t}=\bar{i}_{t-1}+\varepsilon_{t}^{\bar{i}}, \varepsilon_{t}^{\bar{i}} \sim \text { iid } \mathcal{N}\left(0, \sigma_{\bar{i}}^{2}\right), \\
\ln \bar{\tau}_{t}=\ln \bar{\tau}_{t-1}+\varepsilon_{t}^{\bar{\tau}}, \varepsilon_{t}^{\bar{\tau}} \sim \operatorname{iid} \mathcal{N}\left(0, \sigma_{\bar{\tau}}^{2}\right), \\
\ln \overline{\mathcal{E}}_{t}=\ln \overline{\mathcal{E}}_{t-1}+\varepsilon_{t}^{\overline{\mathcal{E}}}, \varepsilon_{t}^{\overline{\mathcal{E}}} \sim \operatorname{iid} \mathcal{N}\left(0, \sigma_{\overline{\mathcal{E}}}^{2}\right) .
\end{gathered}
$$

It follows that along a balanced growth path, the levels of the nominal interest rate, tax rate, and nominal exchange rate are time independent but state dependent. The trend component of the output based real interest rate satisfies $\bar{r}_{t}^{Y}=\bar{i}_{t}-\mathrm{E}_{t} \bar{\pi}_{t+1}^{Y}$, while the trend component of the consumption based real interest rate satisfies $\bar{r}_{t}^{C}=\bar{i}_{t}-\mathrm{E}_{t} \bar{\pi}_{t+1}^{C}$. The trend component of the real exchange rate satisfies $\ln \overline{\mathcal{Q}}_{t}=\ln \overline{\mathcal{E}}_{t}+\ln \bar{P}_{t}^{Y, f}-\ln \bar{P}_{t}^{Y}$, while the trend component of the terms of trade satisfies $\ln \overline{\mathcal{T}}_{\bar{B}^{t}}{ }^{2}=\ln \bar{P}_{t_{G}}^{M^{2}}-\ln \bar{P}_{t}^{X^{z}}$. The trend component of the net government asset position satisfies $\ln \frac{\bar{B}_{t+1}^{t}}{\bar{P}_{\bar{Y}}}=\ln \frac{B^{t_{G}}}{P Y}$, while the trend component of the net foreign asset position satisfies $\ln \frac{B_{t+1}}{\bar{P}_{t} \bar{Y}_{t}}=\ln \frac{\bar{P}_{t}}{P Y}$.

Long run balanced growth is driven by three common stochastic trends. Trend inflation, productivity growth, and population growth follow random walks without drifts:

$$
\begin{aligned}
& \pi_{t}=\pi_{t-1}+\varepsilon_{t}^{\pi}, \varepsilon_{t}^{\pi} \sim \text { iid } \mathcal{N}\left(0, \sigma_{\pi}^{2}\right), \\
& g_{t}=g_{t-1}+\varepsilon_{t}^{g}, \varepsilon_{t}^{g} \sim \text { iid } \mathcal{N}\left(0, \sigma_{g}^{2}\right), \\
& n_{t}=n_{t-1}+\varepsilon_{t}^{n}, \varepsilon_{t}^{n} \sim \text { iid } \mathcal{N}\left(0, \sigma_{n}^{2}\right) .
\end{aligned}
$$

It follows that along a balanced growth path, growth rates are time independent but state dependent. As an identifying restriction, all innovations are assumed to be independent, which combined with our distributional assumptions implies multivariate normality. 


\section{Estimation}

The traditional econometric interpretation of macroeconometric models regards them as representations of the joint probability distribution of the data. We employ a Bayesian estimation procedure which respects this traditional econometric interpretation.

\section{Estimation Procedure}

The parameters and unobserved components of our structural unobserved components model of a small open economy are jointly estimated with a Bayesian procedure, conditional on prior information concerning the values of parameters, and judgment concerning the paths of trend components. Inference on the parameters is based on an asymptotic normal approximation to the posterior distribution around its mode, which is calculated by numerically maximizing the logarithm of the posterior density kernel. Following Engle and Watson (1981), we employ an estimator of the Hessian which depends only on first derivatives and is negative semidefinite.

Evaluation of the logarithm of the posterior density kernel involves first constructing a multivariate linear rational expectations representation of those equations governing the evolution of cyclical components, then solving for the unique stationary solution to this multivariate linear rational expectations model with the algorithm due to Klein (2000). The resultant first order vector autoregressive representation of those equations governing the evolution of cyclical components is then combined with a dynamic factor representation of those equations governing the evolution of trend components to form a linear state space model expressing the levels of all observed nonpredetermined endogenous variables as a function of an unobserved state vector, which in turn evolves according to a first order vector autoregressive process. This linear state space model is then augmented with a set of stochastic restrictions on selected unobserved state variables summarizing judgment concerning the paths of the trend components of all observed nonpredetermined endogenous variables. The logarithm of the predictive density function is then evaluated, conditional on the parameters associated with this linear state space model, with the filter derived in Vitek (2008a, 2008b), which adapts the filter due to Kalman (1960) to incorporate judgment. Finally, the logarithm of this conditional density function is combined with the logarithm of a multivariate normal density function summarizing prior information concerning the values of parameters. For a detailed discussion of this estimation procedure, please refer to Vitek (2008a, 2008b).

\section{Estimation Results}

The set of parameters associated with our structural unobserved components model is partitioned into two subsets. The first subset is calibrated to approximately match sample averages of functions of the levels of observed endogenous variables where possible, or estimates reported in the existing empirical literature where necessary. The second subset is 
estimated with the Bayesian procedure described above, conditional on the levels of thirty one endogenous variables for Hong Kong SAR and the United States observed over the recent Linked Exchange Rate System period spanning 1983Q4 through 2008Q2.

Subjective discount factor $\beta$ is restricted to equal 0.99 , implying an annualized deterministic steady state equilibrium real interest rate of approximately 0.04. In deterministic steady state equilibrium, the output price markup $\frac{\theta^{Y}}{\theta^{Y}}$, export price markup $\frac{\theta^{X}}{\theta^{X} \theta^{Y}}$ and import price markup $\frac{\theta^{M}}{\theta^{M}-1}$ are restricted to equal 1.15, while the wage markup $\frac{\theta^{\mathrm{L}}}{\theta^{L}-1}$ is restricted to equal 1.50. Depreciation rate parameter $\delta$ is restricted to equal 0.025, implying an annualized deterministic steady state equilibrium depreciation rate of approximately 0.10 . In deterministic steady state equilibrium, the consumption import share $1-\phi^{C}$, investment import share $1-\phi^{I}$, and government consumption import share $1-\phi^{G}$ are restricted to equal 0.65 domestically and 0.02 abroad. The deterministic steady state equilibrium ratio of consumption to output $\frac{C}{Y}$ is restricted to equal 0.60 , while the deterministic steady state equilibrium ratio of domestic output to foreign output $\frac{Y}{Y^{f}}$ is restricted to equal 0.015 . In deterministic steady state equilibrium, the entrepôt export share $1-\phi^{X}$ is restricted to equal 0.65 , while the entrepôt import share is restricted to equal 0.55 . The deterministic steady state equilibrium income share of labor $\frac{W L}{P Y}$ is restricted to equal 0.45 domestically and 0.55 abroad. In deterministic steady state equilibrium, the ratio of government consumption to output $\frac{G}{Y}$ is restricted to equal 0.10 domestically and 0.20 abroad, while the tax rate $\tau$ is restricted to equal 0.08 domestically and 0.22 abroad.

Table I.1. Deterministic Steady State Equilibrium Values of Great Ratios 1/

\begin{tabular}{ccc}
\hline Ratio & Hong Kong SAR & United States \\
\hline$C / Y$ & 0.6000 & 0.6225 \\
$I / Y$ & 0.2749 & 0.1775 \\
$G / Y$ & 0.1000 & 0.2000 \\
$X / Y$ & 1.3333 & - \\
$X^{e} / Y$ & 0.8667 & - \\
$M / Y$ & 1.4082 & - \\
$M^{n} / Y$ & 0.6337 & - \\
$W L / P Y$ & 0.4500 & 0.5500 \\
$K / Y$ & 2.7492 & 1.7753 \\
$B^{G} / P Y$ & 0.4950 & -0.4950 \\
$B / P Y$ & 1.8534 & -- \\
\hline
\end{tabular}

1/ Deterministic steady state equilibrium values are reported at an annual frequency based on calibrated parameter values.

Bayesian estimation of the remaining parameters of our structural unobserved components model of a small open economy is based on the levels of thirty one observed endogenous variables for Hong Kong SAR and the United States described in Appendix II. Those parameters associated with the conditional mean function are estimated conditional on 
informative independent priors, while those parameters associated exclusively with the conditional variance function are estimated conditional on diffuse priors. Initial conditions for the cyclical components of exogenous variables are given by their unconditional means and variances, while the initial values of all other state variables are treated as parameters, and are calibrated to match functions of initial realizations of the levels of observed endogenous variables, or preliminary estimates of their trend components calculated with the filter described in Hodrick and Prescott (1997). The posterior mode is calculated by numerically maximizing the logarithm of the posterior density kernel with a modified steepest ascent algorithm. Parameter estimation results pertaining to the period 1983Q4 through 2008Q2 are reported in Table I.2. The sufficient condition for the existence of a unique stationary rational expectations equilibrium due to Klein (2000) is satisfied in a neighborhood around the posterior mode, while our estimator of the Hessian is not nearly singular at the posterior mode, suggesting that the approximate linear state space representation of our structural unobserved components model is locally identified.

Those parameters associated with the conditional mean function are estimated conditional on independent marginal prior distributions centered within the range of estimates reported in related empirical papers such as Christiano, Eichenbaum and Evans (2005) and Smets and Wouters (2003). The prior mean of indexation parameter $\gamma^{Y}$ is 0.50 domestically and 0.75 abroad, implying considerable output price inflation inertia, while the prior mean of nominal rigidity parameter $\omega^{Y}$ implies an average duration of output price contracts of six quarters domestically and eight quarters abroad, during which time output prices are adjusted suboptimally every quarter. The prior mean of capital utilization cost parameter $\kappa$ is 0.10 , while the prior mean of elasticity of substitution parameter $\vartheta$ is 0.50 , implying that utilized capital and effective labor are moderately close complements in production. The prior mean of habit persistence parameter $\alpha^{C}$ is 0.95 , while the prior mean of intertemporal elasticity of substitution parameter $\sigma$ is 2.75, implying that consumption exhibits considerable persistence and moderate sensitivity to real interest rate changes. The prior mean of investment adjustment cost parameter $\chi$ is 5.75, implying moderate sensitivity of investment to changes in the relative shadow price of capital. The prior mean of indexation parameter $\gamma^{M}$ is 0.50 domestically and 0.75 abroad, implying moderate import price inflation inertia, while the prior mean of nominal rigidity parameter $\omega^{M}$ implies an average duration of import price contracts of six quarters domestically and eight quarters abroad, during which time import prices are adjusted suboptimally every quarter. The prior mean of elasticity of substitution parameter $\psi$ is 1.50 , implying that domestic and foreign goods are moderately close substitutes in consumption, investment, and government consumption. The prior mean of indexation parameter $\gamma^{X}$ is 0.75 , implying moderate export price inflation inertia, while the prior mean of nominal rigidity parameter $\omega^{X}$ implies an average duration of export price contracts of six quarters, during which time export prices are adjusted suboptimally every quarter. The prior mean of elasticity of substitution parameter $\psi^{X}$ is 1.50 , implying that nonentrepôt and entrepôt exports are moderately close substitutes in exports, while the prior mean of elasticity of substitution parameter $\psi^{M}$ is 1.50 , implying that nonentrepôt and entrepôt imports are moderately close substitutes in imports. The prior mean of indexation 
parameter $\gamma^{L}$ is 0.50 domestically and 0.75 abroad, implying considerable sensitivity of the real wage to changes in consumption price inflation, while the prior mean of nominal rigidity parameter $\omega^{L}$ implies an average duration of wage contracts of six quarters domestically and eight quarters abroad, during which time wages are adjusted suboptimally every quarter. The prior mean of habit persistence parameter $\alpha^{L}$ is 0.95 , while the prior mean of elasticity of substitution parameter $\eta$ is 0.50 , implying considerable insensitivity of the real wage to changes in employment. The prior mean of the nominal exchange rate response coefficient $\xi^{\mathcal{E}}$ in the domestic monetary policy rule is 1.00 , implying convergence of the level of the nominal exchange rate to its target value. The prior mean of the consumption price inflation response coefficient $\xi^{\pi}$ in the foreign monetary policy rule is 1.50, while the prior mean of the output response coefficient $\xi^{Y}$ is 0.125 , implying convergence of the level of consumption price inflation to its target value. The prior mean of the net foreign asset response coefficient $\zeta^{G}$ in the fiscal expenditure rule is 0.10 , while the prior mean of the net government asset response coefficient $\zeta^{\tau}$ in the fiscal revenue rule is -1.00 domestically and 1.00 abroad, implying convergence of the levels of the ratios of net foreign assets and net government assets to nominal output to their target values. All autoregressive parameters $\rho$ have prior means of 0.85 , implying considerable persistence of shocks driving variation in cyclical components.

Judgment concerning the paths of trend components is generated by passing the levels of all observed endogenous variables through the filter described in Hodrick and Prescott (1997). ${ }^{3}$ Stochastic restrictions on the trend components of all observed endogenous variables are derived from these preliminary estimates, with innovation variances set proportional to the sample variances of cyclical deviations from them. All stochastic restrictions are independent, represented by a diagonal covariance matrix, and are harmonized, represented by a common factor of proportionality. Reflecting little confidence in these preliminary trend component estimates, this common factor of proportionality is set equal to one.

The posterior modes of all structural parameters are close to their prior means, reflecting the imposition of tight independent priors to preserve economically plausible impulse response dynamics. The estimated variances of shocks driving variation in cyclical components are all well within the range of estimates reported in the existing empirical literature, after accounting for data rescaling. The estimated variances of shocks driving variation in trend components are relatively high, indicating that much of the variation in the levels of observed endogenous variables is accounted for by variation in their trend components.

\footnotetext{
${ }^{3}$ Following their recommendation, the smoothness parameter is set to 1600 .
} 
Table I.2. Parameter Estimation Results 1/

\begin{tabular}{|c|c|c|c|c|c|c|c|c|}
\hline \multirow[b]{3}{*}{ Parameter } & \multicolumn{4}{|c|}{ Hong Kong SAR } & \multicolumn{4}{|c|}{ United States } \\
\hline & \multicolumn{2}{|c|}{ Prior } & \multicolumn{2}{|c|}{ Posterior } & \multicolumn{2}{|c|}{ Prior } & \multicolumn{2}{|c|}{ Posterior } \\
\hline & Mean & SE & Mode & SE & Mean & SE & Mode & SE \\
\hline$\alpha^{C}$ & 0.9500 & 0.0095 & 0.8255 & 0.0071 & 0.9500 & 0.0095 & 0.8622 & 0.0078 \\
\hline$\alpha^{L}$ & 0.9500 & 0.0095 & 0.8884 & 0.0084 & 0.9500 & 0.0095 & 0.9241 & 0.0040 \\
\hline$\chi$ & 5.7500 & 0.0575 & 5.4482 & 0.0571 & 5.7500 & 0.0575 & 5.6948 & 0.0575 \\
\hline$\eta$ & 0.5000 & 0.0050 & 0.5024 & 0.0050 & 0.5000 & 0.0050 & 0.5020 & 0.0050 \\
\hline$\kappa$ & 0.1000 & 0.0010 & 0.0993 & 0.0010 & 0.1000 & 0.0010 & 0.0998 & 0.0010 \\
\hline$\sigma$ & 2.7500 & 0.0275 & 2.8209 & 0.0273 & 2.7500 & 0.0275 & 2.7818 & 0.0274 \\
\hline$\vartheta$ & 0.5000 & 0.0050 & 0.4996 & 0.0050 & 0.5000 & 0.0050 & 0.4999 & 0.0050 \\
\hline$\gamma^{Y}$ & 0.5000 & 0.0050 & 0.4989 & 0.0050 & 0.7500 & 0.0075 & 0.7516 & 0.0075 \\
\hline$\gamma^{X}$ & 0.5000 & 0.0050 & 0.5007 & 0.0050 & -- & -- & -- & -- \\
\hline$\gamma^{M}$ & 0.5000 & 0.0050 & 0.5002 & 0.0050 & 0.7500 & 0.0075 & 0.7486 & 0.0075 \\
\hline$\gamma^{L, W}$ & 0.0000 & 0.0100 & 0.0010 & 0.0100 & 0.0000 & 0.0100 & 0.0010 & 0.0099 \\
\hline$\gamma^{L, P}$ & 0.5000 & 0.0050 & 0.5012 & 0.0050 & 0.7500 & 0.0075 & 0.7486 & 0.0075 \\
\hline$\gamma^{L, y}$ & 0.0000 & 0.0100 & 0.0010 & 0.0097 & 0.0000 & 0.0100 & 0.0010 & 0.0099 \\
\hline$\omega^{Y}$ & 0.8333 & 0.0083 & 0.8604 & 0.0073 & 0.8750 & 0.0088 & 0.8486 & 0.0066 \\
\hline$\omega^{X}$ & 0.8333 & 0.0083 & 0.8270 & 0.0083 & -- & -- & -- & -- \\
\hline$\omega^{M}$ & 0.8333 & 0.0083 & 0.8128 & 0.0082 & 0.8750 & 0.0088 & 0.8844 & 0.0082 \\
\hline$\omega^{L}$ & 0.8333 & 0.0083 & 0.9004 & 0.0061 & 0.8750 & 0.0088 & 0.7926 & 0.0057 \\
\hline$\psi$ & 1.5000 & 0.0150 & 1.4947 & 0.0149 & 1.5000 & 0.0150 & 1.7026 & 0.0150 \\
\hline$\psi^{X}$ & 1.5000 & 0.0150 & 1.4993 & 0.0150 & -- & -- & -- & -- \\
\hline$\psi^{M}$ & 1.5000 & 0.0150 & 1.5027 & 0.0150 & -- & -- & -- & -- \\
\hline$\xi^{\pi}$ & -- & -- & -- & -- & 1.5000 & 0.0150 & 1.4859 & 0.0149 \\
\hline$\xi^{Y}$ & -- & -- & -- & -- & 0.1250 & 0.0013 & 0.1251 & 0.0012 \\
\hline$\xi^{\mathcal{E}}$ & 1.0000 & 0.0100 & 1.0027 & 0.0100 & -- & -- & -- & -- \\
\hline$\rho_{i}$ & -- & -- & -- & -- & 0.8500 & 0.0085 & 0.7860 & 0.0074 \\
\hline$\zeta^{G}$ & 0.1000 & 0.0010 & 0.1000 & 0.0010 & -- & -- & -- & -- \\
\hline$\zeta^{\tau}$ & -1.0000 & 0.0100 & -0.9936 & 0.0100 & 1.0000 & 0.0100 & 0.9956 & 0.0100 \\
\hline$\rho_{G}$ & 0.8500 & 0.0085 & 0.8460 & 0.0084 & 0.8500 & 0.0085 & 0.8509 & 0.0083 \\
\hline$\rho_{\tau}$ & 0.8500 & 0.0085 & 0.4208 & 0.0079 & 0.8500 & 0.0085 & 0.8343 & 0.0079 \\
\hline$\rho_{v^{c}}$ & 0.8500 & 0.0009 & 0.8496 & 0.0008 & 0.8500 & 0.0009 & 0.8477 & 0.0008 \\
\hline$\rho_{A}$ & 0.8500 & 0.0009 & 0.8508 & 0.0008 & 0.8500 & 0.0009 & 0.8488 & 0.0008 \\
\hline$\rho_{v^{I}}$ & 0.8500 & 0.0009 & 0.8506 & 0.0008 & 0.8500 & 0.0009 & 0.8490 & 0.0008 \\
\hline$\rho_{v^{M}}$ & 0.8500 & 0.0009 & 0.8489 & 0.0008 & 0.8500 & 0.0009 & 0.8498 & 0.0008 \\
\hline$\rho_{\theta^{r}}$ & 0.8500 & 0.0009 & 0.8499 & 0.0009 & 0.8500 & 0.0009 & 0.8494 & 0.0008 \\
\hline$\rho_{\theta^{x}}$ & 0.8500 & 0.0009 & 0.8500 & 0.0009 & -- & -- & -- & -- \\
\hline$\rho_{\theta^{M}}$ & 0.8500 & 0.0009 & 0.8499 & 0.0009 & 0.8500 & 0.0009 & 0.8500 & 0.0009 \\
\hline$\rho_{\theta^{L}}$ & 0.8500 & 0.0009 & 0.8500 & 0.0009 & 0.8500 & 0.0009 & 0.8486 & 0.0008 \\
\hline$\rho_{f}$ & 0.8500 & 0.0009 & 0.8485 & 0.0008 & -- & -- & -- & -- \\
\hline$\sigma_{v^{c}}^{2}$ & -- & $\infty$ & 0.2024 & 0.0393 & -- & $\infty$ & 0.4898 & 0.1016 \\
\hline$\sigma_{A}^{2}$ & -- & $\infty$ & 0.2613 & 0.0412 & -- & $\infty$ & 0.1684 & 0.0254 \\
\hline$\sigma_{v^{I}}^{2}$ & -- & $\infty$ & 0.0868 & 0.0199 & -- & $\infty$ & 0.2600 & 0.0562 \\
\hline$\sigma_{v^{M}}^{2}$ & -- & $\infty$ & 0.1439 & 0.0254 & -- & $\infty$ & 0.2622 & 0.0582 \\
\hline$\sigma_{\theta^{Y}}^{2}$ & -- & $\infty$ & 0.2497 & 1.6143 & -- & $\infty$ & 0.2350 & 0.2923 \\
\hline$\sigma_{\theta^{x}}^{2}$ & -- & $\infty$ & 0.2503 & 1.3310 & -- & -- & -- & -- \\
\hline$\sigma_{\theta^{m}}^{2}$ & -- & $\infty$ & 0.2518 & 0.7224 & -- & $\infty$ & 0.2567 & 2.7478 \\
\hline$\sigma_{\theta^{L}}^{2}$ & -- & $\infty$ & 0.2493 & 1.0051 & -- & $\infty$ & 0.3353 & 0.0802 \\
\hline$\sigma_{v^{i}}^{2}$ & -- & $\infty$ & 0.2743 & 0.0402 & -- & $\infty$ & 0.0178 & 0.0027 \\
\hline$\sigma_{v^{G}}^{2}$ & -- & $\infty$ & 0.2428 & 0.0764 & -- & $\infty$ & 0.2790 & 0.0448 \\
\hline$\sigma_{v^{\tau}}^{2}$ & -- & $\infty$ & 4.9741 & 0.6815 & -- & $\infty$ & 0.2408 & 0.0352 \\
\hline
\end{tabular}


Table I.2. Parameter Estimation Results 1/

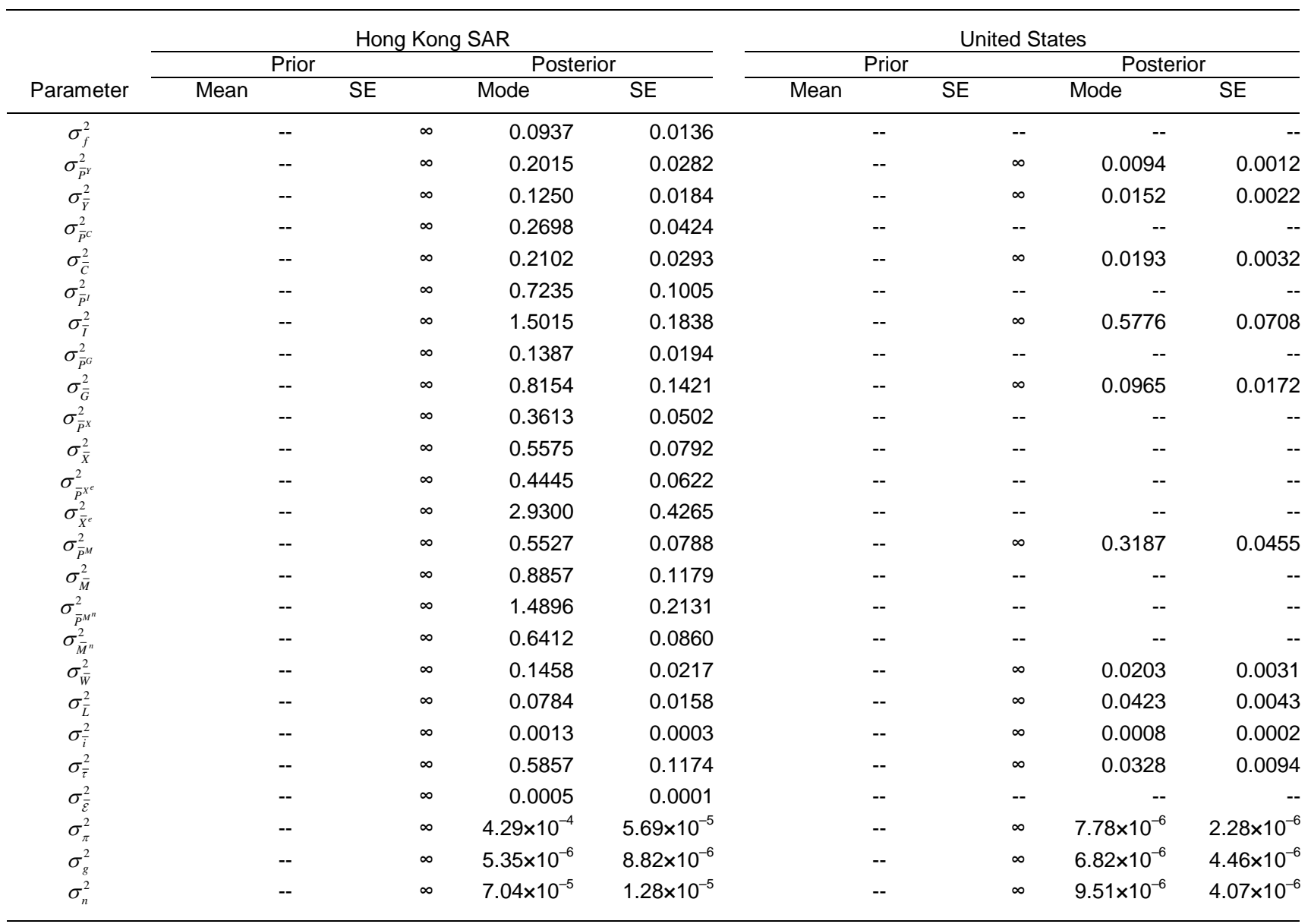

1/ All observed endogenous variables are rescaled by a factor of 100 . 


\section{APPENDIX II. DESCRIPTION OF THE DATA SET}

The data set consists of quarterly seasonally adjusted observations on thirty one macroeconomic variables for Hong Kong SAR and the United States over the period 1983Q4 through 2008Q2. All aggregate prices and quantities are expenditure based. The nominal interest rate is measured by the three month money market rate expressed as a period average, while the nominal exchange rate is quoted as an end of period value. Data for Hong Kong was obtained from the CEIC database maintained by Internet Securities Incorporated, while data for the United States was extracted from the FRED database maintained by the Federal Reserve Bank of Saint Louis. 


\section{References}

Calvo, G., 1983, “Staggered Prices in a Utility-Maximizing Framework,” Journal of Monetary Economics, Vol. 12, pp. 983-998.

Christiano, L., M. Eichenbaum, and C. Evans, 2005, "Nominal Rigidities and the Dynamic Effects of a Shock to Monetary Policy,” Journal of Political Economy, Vol. 113, pp. $1-45$.

Engle, R. and M. Watson, 1981, “A One-Factor Multivariate Time Series Model of Metropolitan Wage Rates,” Journal of the American Statistical Association, Vol. 76, pp. 774-781.

Erceg, C., D. Henderson, and A. Levin, 2000, “Optimal Monetary Policy with Staggered Wage and Price Contracts,” Journal of Monetary Economics, Vol. 46, pp. 281-313.

Hodrick, R. and E. Prescott, 1997, "Post-War U.S. Business Cycles: A Descriptive Empirical Investigation,” Journal of Money, Credit, and Banking, Vol. 29, pp. 1-16.

Kalman, R., 1960, “A New Approach to Linear Filtering and Prediction Problems,” Transactions ASME Journal of Basic Engineering, Vol. 82, pp. 35-45.

Klein, P., 2000, “Using the Generalized Schur Form to Solve a Multivariate Linear Rational Expectations Model,” Journal of Economic Dynamics and Control, Vol. 24, pp. 1405-1423.

Monacelli, T., 2005, “Monetary Policy in a Low Pass-Through Environment,” Journal of Money, Credit, and Banking, Vol. 37, pp. 1047-1066.

Porter, N. and F. Vitek, 2008, “A Structural Analysis of Saving and Investment Dynamics in Hong Kong SAR,” IMF Working Paper (forthcoming) (Washington: International Monetary Fund).

Smets, F. and R. Wouters, 2003, “An Estimated Dynamic Stochastic General Equilibrium Model of the Euro Area," Journal of the European Economic Association, Vol. 1, pp. 1123-1175.

Vitek, F., 2008a, Monetary Policy Analysis: Development and Evaluation of Quantitative Tools, (Hyderabad, India: ICFAI University Press).

— 2008b, Monetary Policy Analysis in a Small Open Economy: Development and Evaluation of Quantitative Tools, (Germany: Vdm Verlag). 